\title{
The interaction of LOXL2 with GATA6 induces VEGFA expression and angiogenesis in cholangiocarcinoma
}

\author{
TAO PENG ${ }^{1,2}$, XIANG DENG ${ }^{1}$, FENG TIAN ${ }^{1}$, ZHONGHU LI $^{1}$, PENG JIANG ${ }^{1}$, XIN ZHAO ${ }^{1}$, GUANGYU CHEN ${ }^{1}$, \\ YAN CHEN $^{1}$, PING ZHENG ${ }^{1}$, DAJIANG LI ${ }^{1}$ and SHUGUANG WANG ${ }^{1}$ \\ ${ }^{1}$ Hepatobiliary Surgery Institute, Southwest Hospital, Army Medical University, Chongqing 400038; \\ ${ }^{2}$ Department of Hepatobiliary Surgery, The First Affiliated Hospital of Yangtze University, \\ Jingzhou, Hubei 434000, P.R. China
}

Received January 24, 2019; Accepted June 27, 2019

DOI: $10.3892 /$ ijo.2019.4837

\begin{abstract}
Cholangiocarcinoma (CCA) is the second most common hepatobiliary cancer after hepatocellular carcinoma. Antiangiogenic therapy has been administered to patients with CCA, but the benefits of this therapy remain unsatisfactory. Improved understanding of the molecular mechanisms underlying angiogenesis in CCA is required. In the present study, the expression of GATA-binding protein 6 (GATA6), lysyl oxidase-like 2 (LOXL2) and vascular endothelial growth factor A(VEGFA), in addition to the microvessel density (MVD), were evaluated by performing immunohistochemical staining of human CCA microarrays. The expression of GATA6/LOXL2 was associated with poor overall survival $(\mathrm{P}=0.01)$ and disease-free survival $(\mathrm{P}=0.02)$, and was positively associated with VEGFA expression $(\mathrm{P}=0.02)$ and MVD $(\mathrm{P}=0.04)$. In vitro, western blotting, reverse transcription-quantitative PCR analysis and ELISAs revealed that altered GATA6 and LOXL2 expression regulated the expression levels of secreted VEGFA. Co-immunoprecipitation demonstrated a physical interaction between GATA6 and LOXL2 in CCA cell lines, and the scavenger receptor cysteine-rich domain of LOXL2 interacted with GATA6, which regulated VEGFA mRNA expression and protein secretion, and promoted tube formation. In vivo analyses further revealed that GATA6/LOXL2 promoted VEGFA expression, angiogenesis and tumor growth. The GATA6/LOXL2 complex represents a novel candidate prognostic marker for stratifying patients with CCA. Drugs
\end{abstract}

Correspondence to: Professor Shuguang Wang or Professor Dajiang Li, Hepatobiliary Surgery Institute, Southwest Hospital, Army Medical University, 30 Gaotanyan Street, Shapingba, Chongqing 400038, P.R. China

E-mail: sgwangxnyy@sina.com

E-mail: ldjcq@qq.com

Key words: microvessel density, GATA-binding protein 6, lysyl oxidase-like 2, vascular endothelial growth factor A, cholangiocarcinoma targeting this complex may possess great therapeutic value in the treatment of CCA.

\section{Introduction}

Cholangiocarcinoma (CCA), which has a poor prognosis, is the second most common hepatobiliary cancer after hepatocellular carcinoma, and the overall incidence of CCA is increasing globally (1-3). Surgical resection or liver transplantation is the preferred treatment for patients with early-stage CCA, but only some of these patients $(\sim 35 \%)$ are candidates for surgical resection with a curative intent (4). Even for patients who received the first standard chemotherapy for CCA, the median overall survival rates were only 11.7 months and 8.1 months in the cisplatin-gemcitabine and gemcitabine groups, respectively (5). Therefore, improved understanding of the molecular characteristics and biology of CCA will aid the identification of more specific molecular-targeted therapies.

Angiogenesis, which is defined as the formation of new blood vessels from pre-existing vasculature, has become a well-established hallmark of cancer $(6,7)$. Angiogenesis maintains the aggressive growth and metastasis of tumors by supplying nutrients and oxygen (8). Vascular endothelial growth factor A (VEGFA) serves an important role in tumor angiogenesis and correlates with vessel count in various solid cancers (9-11). Patients with solid tumors with a high microvessel density (MVD) exhibited shorter survival than patients with a low MVD (12-16). Antiangiogenic therapy has been clinically administered to treat various solid tumors (17), including CCA $(18,19)$; however, the clinical benefits of antiangiogenic therapy for cancer remain unsatisfactory, and high rates of clinical side effects, cytotoxicity, acquired resistance and patient relapse have been reported $(17,20,21)$. Thus, novel treatments that address mechanisms of angiogenesis are urgently required.

GATA-binding protein 6 (GATA6) is a member of the GATA-binding protein family that shares two highly conserved zinc finger-containing transcription factors (22). GATA6 is essential for the proliferation, differentiation and development of the cardiovascular system, digestive system, and other tissues during embryonic development (23). Tumorigenesis is closely associated with gene activation in the embryonic stage (24), and overexpression of GATA6 promotes the tumorigenicity of 
gastric cancer (25), colorectal cancer (26), pancreatic cancer (27) and breast cancer (28). Certain studies have linked GATA6 to angiogenesis (29-31); however, the molecular mechanisms via which GATA6 regulates angiogenesis in cancer are yet to be investigated.

Lysyl oxidase-like 2 (LOXL2) is a member of the LOX family of extracellular matrix-modifying enzymes, which includes the prototypic LOX and four different LOX-like proteins (LOXL1, LOXL2, LOXL3 and LOXL4) (32). The C-terminal region of LOXL2 is responsible for its enzymatic activity, and the $\mathrm{N}$-terminus contains four scavenger receptor cysteine-rich (SRCR) domains that are proposed to be involved in protein-protein interactions (33). Intranuclear LOXL2 cooperates with certain transcription factors to regulate the epithelial-mesenchymal transition (EMT) and promote tumor metastasis $(34,35)$. Furthermore, targeted inhibition of LOXL2 decreases angiogenesis in rodent models of tumors and ophthalmic disease $(36,37)$; however, the angiogenic mechanisms of LOXL2 in CCA are yet to be investigated.

As reported in our previous studies, GATA6 and LOXL2 promote invasion and metastasis in CCA via distinct mechanisms $(38,39)$; however, an interaction between GATA6 and LOXL2 has not yet been reported. In the present study, in silico analysis was conducted to reveal that GATA6 may bind to the VEGFA promoter. It was then demonstrated that GATA6 transcriptionally regulated VEGFA expression, and a novel mechanism of angiogenesis in CCA was elucidated, in which LOXL2 interacted with GATA6 to promote angiogenesis and tumor growth.

\section{Materials and methods}

Patients and clinical samples. A total of 91 patients (48 males and 43 females aged 32-76 years old) with CCA who underwent surgical resection at Southwest Hospital between 2013 and 2016 were included; 91 cancerous samples and 31 paracancerous samples were obtained. The clinical and pathological characteristics of the patients are presented in Tables I and SI. None of the patients received radiotherapy or chemotherapy prior to or following surgery. TNM staging was conducted using the 7th Union for International Cancer Control TNM staging system (40). The present study was approved by the Ethics Committee of Southwest Hospital at Army Medical University. The participants provided written informed consent, and this study was conducted in accordance with the Declaration of Helsinki.

Tissue microarray (TMA) and immunohistochemistry (IHC). Clinical tissues specimens were fixed in $4 \%$ paraformaldehyde for $24 \mathrm{~h}$ at room temperature, and then dehydrated and embedded in paraffin. Each TMA containing 91 cancerous and 31 paracancerous paraffin-embedded samples was constructed by Shanghai Outdo Biotech Co., Ltd.; 1.5-mm diameter and $4-\mu \mathrm{m}$ thick sample tissues were constructed. Immunostaining was performed using a GTVion ${ }^{\mathrm{TM}}$ Detection System/Mo\&Rb (cat. no. GK500710; Shanghai Genetech Co., Ltd.) according to the manufacturer's protocol. CCA TMAs were incubated at $60^{\circ} \mathrm{C}$ for $90 \mathrm{~min}$ to melt the wax and were deparaffinized twice with xylene for $10 \mathrm{~min}$ each, followed by rehydration in a descending graded ethanol series and PBS (5 min per grade).
For antigen retrieval, TMAs were heated for $10 \mathrm{~min}$ in sodium citrate buffer ( $\mathrm{pH}$ 6.0). Endogenous peroxidases were blocked with $3 \% \mathrm{H}_{2} \mathrm{O}_{2}$ for $30 \mathrm{~min}$, and non-specific binding was blocked with 5\% BSA (cat. no. ST023; Beyotime) for $30 \mathrm{~min}$ at room temperature followed by incubation with primary antibodies overnight at $4^{\circ} \mathrm{C}$ in a humidified chamber. GATA6 (1:50; cat. no. NBP1-47766; Novus Biologicals LLC), LOXL2 (1:100; cat. no. ab96233), VEGFA (1:200; cat. no. ab46154) and CD34 (1:100; cat. no. ab81289) (all from Abcam) primary antibodies were used. Appropriate anti-mouse/anti-rabbit secondary antibodies from the Detection System kit conjugated to horseradish peroxidase (HRP) were then added for $1 \mathrm{~h}$ at $37^{\circ} \mathrm{C}$. Expression was detected with 3,3'-diaminobenzidine substrate for $10 \mathrm{sec}$, and the reaction was stopped with PBS. Hematoxylin was used to stain nuclei for $30 \mathrm{sec}$ at room temperature, and the reaction was stopped by PBS. TMAs were dehydrated in an ascending graded ethanol series (5 min per step), followed by washing with xylene twice for $10 \mathrm{~min}$ each. After the slices were dried, a coverslip was mounted onto the slides with neutral balsam (cat. no. G8590; Beijing Solarbio Science \& Technology Co., Ltd.). Each sample was observed under a light microscope (magnification, $\mathrm{x} 40$ and $\mathrm{x} 400$; BX41; Olympus Corporation), and three fields per sample were analyzed. The protocol and reagents used for IHC of subcutaneous tumors were as aforementioned.

GATA6 and LOXL2 expression levels were evaluated based on the nuclear score, and VEGFA expression was evaluated based on the cytoplasmic score calculated by two observers without knowledge of the patients' clinical characteristics. The staining intensity was scored as follows: 0 (negative), 1 (weak), 2 (moderate) or 3 (strong staining). The percentage of positively stained cells was calculated by comparing the number of positively stained cells to the number of nuclei $(0$, no cells stained; $1,1-25 \% ; 2,26-50 \%$; and 3, $>50 \%$ ). The final score was obtained by adding the intensity score and the positivity score. A score of 0-1 was defined as negative expression (-), a score of 2-4 was defined as weak positive expression (+), and a score of 5-6 was defined as strong positive expression (++).

MVD. An anti-CD34 antibody was used to stain endothelial cells and analyze tumor-associated angiogenesis as aforementioned. The MVD was measured according to the method described by Weidner et al (41), and was assessed by two observers without knowledge of the patient's clinicopathological characteristics. The three highest density vessel fields (hot spots) were identified under a light microscope at low power (magnification, x100). Any CD34-stained endothelial cells or clusters of endothelial cells were defined as an individual, countable microvessel. The number of microvessels was determined (magnification, $\mathrm{x} 400$ ), and the MVD was presented as the number of vessels $/ \mathrm{mm}^{2}$. For each slide, the average MVD of vascular hot spots was calculated based on the vessel count.

Cell culture and lentivirus infection. The human CCA cell line QBC939 was established from an extrahepatic CCA lesion and maintained at the Hepatobiliary Surgery Institute, Southwest Hospital, Army Medical University. RBE cells were purchased from the Japanese Collection of Research Bioresources Cell Bank (39). The two human CCA cell lines were cultured in RPMI 1640 medium (Gibco; Thermo Fisher Scientific, Inc.) 
supplemented with $10 \%$ fetal bovine serum (FBS; Zeta Life). Human umbilical vein endothelial cells (HUVECs) were purchased from the American Type Culture Collection and cultured in DMEM (Gibco; Thermo Fisher Scientific, Inc.) supplemented with $10 \%$ FBS.

QBC939 cells were infected with lentiviral vectors (LV1-shGATA6 and LV10-shLOXL2) encoding short hairpin RNAs (shRNAs) targeting human GATA6 and/or LOXL2 (shGATA6, shLOXL2 and shGATA6/LOXL2) or scrambled shRNA (LV1-shControl and LV10-shControl), which served as a control (shControl; all from Shanghai GenePharma Co., Ltd.). shRNAs were inserted into LV1 or LV10 plasmids (Shanghai GenePharma Co., Ltd.). RBE cells were infected with lentiviral vectors (LV5-GATA6 and LV8-LOXL2) containing LV5 or LV8 plasmids (Shanghai GenePharma Co., Ltd.) overexpressing human GATA6 and/or LOXL2 (exGATA6, exLOXL2 or exGATA6/LOXL2), or containing empty vector (LV5 or LV8), which served as a control (exControl; all from Shanghai GenePharma Co., Ltd.). In total, $1 \times 10^{5}$ CCA cells were seeded in 6-well plates overnight. After the cells were rinsed with sterile PBS, $100 \mu 1$ ( $10^{7}$ units) lentivirus particles and $2 \mu \mathrm{l}(5 \mu \mathrm{g} / \mu \mathrm{l})$ polybrene (Shanghai GenePharma Co., Ltd.) were added to $2 \mathrm{ml}$ RPMI-1640 medium for transfection. Fresh medium was added after $24 \mathrm{~h}$. Cells were cultured for another $48 \mathrm{~h}$, and the transfection efficiency was assessed. These cells were used in subsequent experiments. The shRNA sequences are listed in Table SII.

Plasmid constructs and transfection. Plasmids (pcDNA3.1 backbone) containing the full-length (Flag-LOXL2-full) and different deletion mutants of LOXL2 (Flag-LOXL2- $\Delta 1$ : deleted aa 548-774; Flag-LOXL2- $\Delta 2$ : deleted aa 1-547) were constructed by Shanghai Genechem Co., Ltd. QBC939 or RBE cells at $70-80 \%$ confluency in $10-\mathrm{cm}$ diameter dishes were transfected with $20 \mu \mathrm{g}$ plasmids using the Lipofectamine ${ }^{\mathrm{TM}} 3000$ reagent (Invitrogen; Thermo Fisher Scientific, Inc.). Cells were cultured for $72 \mathrm{~h}$ after transfection. The collected cells were used for co-IP according to the subsequent protocol.

Dual-luciferase reporter assay. QBC939 cells at 70-80\% confluency in 96-well plates were transfected with $0.1 \mu \mathrm{g}$ shRNA plasmids [shControl, shGATA6, shLOXL2 or shGATA6/LOXL2 in pGPU6 vectors (Shanghai GenePharma Co.,Ltd.)], $0.1 \mu \mathrm{g}$ 2-kb pGL3-VEGFA promoter firefly luciferase plasmid (Shanghai GenePharma Co., Ltd.) and $0.01 \mu \mathrm{g}$ pGL4.74-TK Renilla luciferase plasmid (Promega Corporation). Plasmids were transfected using the Lipofectamine ${ }^{\mathrm{TM}} 3000$ reagent (Invitrogen; Thermo Fisher Scientific, Inc.). After 48 h, luciferase activity was detected with a Dual-Glo ${ }^{\circledR}$ Luciferase Assay system (cat. no. E2920; Promega Corporation) using Renilla luciferase for normalization.

RBE cells were transfected with GATA6, LOXL2, or GATA6/LOXL2 overexpression plasmids, or an empty plasmid as a control (pcDNA3.1(+) vector; Shanghai GenePharma Co., Ltd.). The luciferase activity of the VEGFA promoter was measured as described above. For LOXL2 mutant plasmids, $\mathrm{RBE}$ cells in 96-well plate were transfected with $0.1 \mu \mathrm{g}$ mutant plasmids, $0.1 \mu \mathrm{g}$ GATA6 plasmid, $0.1 \mu \mathrm{g}$ pGL3-VEGFA promoter firefly luciferase plasmid and $0.01 \mu \mathrm{g}$ pGL4.74-TK Renilla luciferase plasmid. The luciferase activity of the
VEGFA promoter was measured as described above. The experiments were performed in triplicate.

Chromatin immunoprecipitation (ChIP). ChIP was performed according to the EZ-Magna $\mathrm{ChIP}^{\mathrm{TM}} \mathrm{A} / \mathrm{G}$ kit protocol (cat. no. 17-10086; Merck KGaA). CCA cells at 80-90\% confluency in a $15-\mathrm{cm}$ culture dish containing $20 \mathrm{ml}$ medium were incubated for $10 \mathrm{~min}$ at room temperature with $37 \%$ formaldehyde $(550 \mu \mathrm{l})$ for cross-linking. The reaction was quenched by the addition of $2 \mathrm{ml} 2 \mathrm{X}$ glycine. Then, the cells were washed with cold PBS and were collected with a cell scraper. The collected cells were lysed with cell lysis buffer (included in the ChIP A/G kit) and chromatin was sheared to fragments of $200-1,000 \mathrm{bp}$ by sonication for 14 cycles at $200 \mathrm{~W}$ on ice (cycles of $9 \mathrm{sec}$ on followed by $9 \mathrm{sec}$ off). Then, $3 \mu \mathrm{g}$ of rabbit anti-GATA6 (cat. no. 5851; Cell Signaling Technology, Inc.) or rabbit IgG control antibody (cat. no. 2729; Cell Signaling Technology, Inc.) were adsorbed onto protein $\mathrm{G}$ magnetic beads and incubated with chromatin extract at $4^{\circ} \mathrm{C}$ overnight. Cross-linking of DNA fragments was reversed with ChIP elution buffer, and subsequent incubation at $62^{\circ} \mathrm{C}$ for $2 \mathrm{~h}$ and $95^{\circ} \mathrm{C}$ for $15 \mathrm{~min}$. Then, DNA was purified in spin columns by sequentially using bind reagent $\mathrm{A}$, wash reagent $\mathrm{B}$ and elution buffer $\mathrm{C}$ from the kit, and the spin columns were centrifuged at $12,000 \mathrm{x}$ g for $30 \mathrm{sec}$ at room temperature.

Purified DNA was subjected to RNase treatment and analyzed via quantitative (q)PCR. the qPCR reaction was conducted in $25 \mu \mathrm{l}$ of reaction buffer containing $12.5 \mu \mathrm{l} \mathrm{SYBR}$ Premix Ex Taq ${ }^{\mathrm{TM}}$ II (cat. no. RR820A; Takara Bio, Inc.), $2 \mu \mathrm{l}$ of $10 \mu \mathrm{M}$ forward and reverse primers, $2 \mu \mathrm{l}$ purified DNA

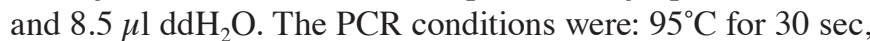
followed by 40 cycles of amplification at $95^{\circ} \mathrm{C}$ for $5 \mathrm{sec}$ and $60^{\circ} \mathrm{C}$ for $30 \mathrm{sec}$. Then, the samples were electrophoresed on $1.5 \%(w / v)$ agarose gels and stained with Gel-Red (cat. no. D0139; Beyotime Institute of Biotechnology) in TAE buffer. Primers targeting the VEGFA promoter are presented in Table SIII.

Co-immunoprecipitation (Co-IP). QBC939 or RBE cells at $80-90 \%$ confluency in two $10-\mathrm{cm}$ diameter dishes were scraped on ice into cold phosphate-buffered saline (PBS), pooled and lysed with $1 \mathrm{ml}$ of Pierce ${ }^{\mathrm{TM}}$ IP lysis buffer (Thermo Fisher Scientific, Inc.) supplemented with protease inhibitors (Roche Diagnostics). Protein G magnetic beads (Bio-Rad Laboratories, Inc.) were washed three times with PBS-0.1\% Tween-20 and incubated with $3 \mu \mathrm{g}$ of antibody in a final volume of $200 \mu \mathrm{l}$ for $30 \mathrm{~min}$ at room temperature. The beads were washed three times and incubated overnight at $4^{\circ} \mathrm{C}$. The beads were washed again, and $30 \mu \mathrm{l}$ of $1 \mathrm{X}$ loading buffer was added. The slurry was incubated at $100^{\circ} \mathrm{C}$ for $10 \mathrm{~min}$, and the beads were discarded. The supernatant was collected for western blotting conducted as described below. The following antibodies were used: GATA6 (cat. no. 5851; Cell Signaling Technology, Inc.); LOXL2 (cat. no. MAB2639; R\&D Systems, Inc.); Flag (cat. no. 14793; Cell Signaling Technology, Inc.); rabbit IgG (cat. no. bs-0295P; BIOSS), and mouse IgG (cat. no. bs-0296P; BIOSS). HRP-conjugated VeriBlot for IP $(1: 1,000$; cat. no. ab131366; Abcam) was used as the secondary antibody, and the membrane was incubated for $2 \mathrm{~h}$ at room temperature. 
$R N A$ isolation and reverse transcription $(R T)-q P C R$. Total RNA from cells was extracted using an Eastep Super Total RNA Extraction kit (Promega Corporation) according to the manufacturer's protocols. RT was performed according to the manufacturer's protocols (PrimeScript ${ }^{\mathrm{TM}} \mathrm{RT}$ reagent kit; cat. no. RR037A; Takara Bio, Inc.). qPCR was performed with SYBR Premix Ex Taq ${ }^{\mathrm{TM}}$ II (cat. no. RR820A; Takara Bio, Inc.) using a CFX96 Real-Time system (Bio-Rad Laboratories, Inc.). The PCR conditions for all assays were: $95^{\circ} \mathrm{C}$ for $30 \mathrm{sec}$, followed by 40 cycles of amplification at $95^{\circ} \mathrm{C}$ for $5 \mathrm{sec}$ and $60^{\circ} \mathrm{C}$ for $30 \mathrm{sec}$. GAPDH mRNA was used to normalize the RNA input. The relative mRNA expression of indicated genes was using the $2^{-\Delta \Delta \mathrm{Cq}}$ method (42). The primer sequences are presented in Table SIII.

Western blotting. Total protein was extracted from cells using RIPA lysis buffer (Sigma-Aldrich; Merck KGaA) containing protease inhibitors (Roche Diagnostics); the protein concentration was measured using a BCA reagent kit (Beyotime Institute of Biotechnology). Equal amounts of protein (30 $\mu \mathrm{g} /$ lane) were separated via 5-10\% SDS-PAGE and transferred to PVDF membranes (Merck KGaA). Membranes were blocked with TBST with $0.1 \%$ Tween-20 containing 5\% nonfat milk for $2 \mathrm{~h}$ at room temperature, and incubated overnight at $4^{\circ} \mathrm{C}$ with the following primary antibodies: Anti-GATA6 (1:2,000; cat. no. 5851; Cell Signaling Technology, Inc.); anti-GAPDH (1:10,000; cat. no. 10494-1-AP; ProteinTech Group, Inc.); anti-LOXL2 (1:2,000; cat. no. ab96233; Abcam); anti-VEGFA (1:2,000; ab46154; Abcam); and anti-Flag (1:1,000; cat. no. 14793, Cell Signaling Technology, Inc.). Membranes were washed with TBST for $30 \mathrm{~min}$ and incubated with an HRP-conjugated anti-rabbit secondary antibody (1:4,000; cat. no. ab6721; Abcam) for $2 \mathrm{~h}$ at room temperature. The immunocomplexes were visualized using the Immobilon ${ }^{\mathrm{TM}}$ Western Chemiluminescent HRP substrate (cat. no. WBKLS0100; Merck KGaA). ImageJ v1.51 software (National Institutes of Health) was used to quantify protein expression level.

Immunofluorescence (IF) and confocal microscopy. CCA cells $\left(1 \times 10^{4}\right)$ were seeded on chamber slides overnight, fixed with $4 \%$ formaldehyde for $15 \mathrm{~min}$ at room temperature, permeabilized with $0.3 \%$ Triton X-100 for 10 min and blocked with $1 \%$ BSA (cat.no.ST023; Beyotime Institute of Biotechnology) for $30 \mathrm{~min}$ at room temperature. Cells were incubated with the following primary antibodies overnight at $4^{\circ} \mathrm{C}$ : Anti-GATA6 (1:100; cat. no. AF1700; R\&D Systems, Inc.) and anti-LOXL2 (1:200; cat. no. ab179810; Abcam). Cells were washed three times and incubated with Cyanine3-conjugated donkey anti-goat (1:50; cat. no. SA00009-3) and Alexa Fluor ${ }^{\circledR} 488$-conjugated donkey anti-rabbit (1:50; cat. no. SA00006-6) secondary antibodies (ProteinTech Group, Inc.) for $1 \mathrm{~h}$ at $37^{\circ} \mathrm{C}$ in dark, and nuclei were stained with DAPI (Beyotime Institute of Biotechnology) for $5 \mathrm{~min}$ at room temperature. A coverslip was mounted onto the slides, which were stored at $4^{\circ} \mathrm{C}$ in the dark. Cells were imaged using a confocal laser scanning microscopy (Leica Microsystem $\mathrm{GmbH}$ ). Three fields per section were photographed (magnification, x200).

Preparation of conditioned medium (CM). QBC939 cells transduced with lentiviruses carrying shRNAs were cultured in 6-well plates as described above. The medium was removed $48 \mathrm{~h}$ later, and the cells were washed three times with PBS and cultured in serum-free RPMI-1640 medium for $24 \mathrm{~h}$. This serum-free medium was then centrifuged at $12,000 \mathrm{x} \mathrm{g}$ for 10 min at $4^{\circ} \mathrm{C}$ to obtain the $\mathrm{CM}$, and stored at $-80^{\circ} \mathrm{C}$ until use.

Enzyme-linked immunosorbent assay (ELISA). The levels of VEGFA in the CM were detected using an ELISA kit (cat. no. AE11718HU; Wuhan Abebio Science Co., Ltd.) according to the manufacturer's protocols. Standard curves were created using purified VEGFA.

In vitro Matrigel-based angiogenesis assays. HUVECs were cultured in 24-well plates coated with Matrigel (Corning Inc.) at a density of $1 \times 10^{5}$ cells/well with CM prepared as described above for $10 \mathrm{~h}$ at $37^{\circ} \mathrm{C}$. Tubes were imaged using an inverted microscope (Nikon Corporation). A total of ten random fields per sample were photographed (magnification, $x 4$ ). The number of connected tubes was determined and then compared between groups.

CCA cell subcutaneous tumorigenesis in nude mice. All animal experiments were approved by the Institutional Animal Care and Use Committee of Southwest Hospital. A total of 20 female nude (BALB/c-nude) mice (age, 4-6 weeks; weight, 20-25 g) were randomly divided into 4 groups and were housed under specific pathogen-free conditions (temperature, 24-26 ${ }^{\circ}$; humidity, 40-60\%; ventilation, 15 times/h; 12:12-h light/dark cycle; free access to food and water). To evaluate whether GATA6/LOXL2 affects tumor angiogenesis, $~ 1 \times 10^{6}$ lentivirus-transfected CCA cells were subcutaneously injected into the right groin region of nude mice. Each group (shControl, shGATA6, shLOXL2 and shGATA6/LOXL2 group) consisted of five mice. All mice were sacrificed via cervical dislocation after 4 weeks. Tumor size was measured using calipers, and tumor volume was calculated according to a formula (length $\mathrm{x}$ width ${ }^{2} \mathrm{x} 1 / 2$ ). The maximum tumor volume reached $0.82 \mathrm{~cm}^{3}$ and no mice developed multiple tumors. All mice maintained good body condition throughout the experiment. Tumor tissues were soaked in 4\% paraformaldehyde for $24 \mathrm{~h}$ at room temperature, and then dehydrated and embedded in paraffin. The samples were sliced into $4 \mu \mathrm{m}$ thickness and stained as described above.

Hematoxylin-eosin $(H \& E)$ staining. Tissue sections of subcutaneous tumors were stained with $\mathrm{H} \& \mathrm{E}$ according to the manufacturer's protocols (cat. no. BL700B; Biosharp Inc.). Deparaffinization and rehydration of sections were performed as previously described. Then, the sections were stained with hematoxylin for $30 \mathrm{sec}$ at room temperature, and followed by eosin staining for $30 \mathrm{sec}$ at room temperature. The sections were observed under a light microscope (Olympus BX41, Japan) at x200 magnification.

Statistical analysis. Data were analyzed using SPSS 22.0 software (IBM Corp.). Survival curves were analyzed with the Kaplan-Meier method, and the log rank test was used to evaluate overall survival and disease-free survival. Multivariate analysis was performed using the Cox proportional hazard regression model. Student's two-tailed t-test was used to compare the 
mean value of two groups. Comparisons among multiple groups were made using ANOVA followed by least significant difference post hoc test. For categorical data, a $\chi^{2}$ analysis or Fisher's exact test was used. The data are presented as the mean \pm SEM. $\mathrm{P}<0.05$ was considered to indicate a statistically significant difference.

\section{Results}

Expression and localization of GATA6 and LOXL2 in human CCAtissues.IHC staining was performed to analyze GATA6 and LOXL2 expression levels in two TMAs. GATA6 was exclusively located in the nucleus; however, LOXL2 was detected in both the nucleus and cytoplasm. The scores for the two proteins were calculated in the nucleus only (Fig. 1A). All paracancerous samples were negative for GATA6, LOXL2 and VEGFA staining in bile duct epithelium (Fig. 1B). Among these CCA TMA samples, 38 samples that were weakly or strongly positive for GATA6 and LOXL2 were defined as double-positive, which was designated as GATA6/LOXL2-positive; 28 were defined as double-negative (GATA6/LOXL2-negative). The remaining 25 cases included 12 GATA6-negative/LOXL2-positive and 13 GATA6-positive/LOXL2-negative samples (Table SI).

GATA6/LOXL2-positive expression is associated with poor prognosis in patients with CCA. Our previous studies reported that aberrant expression of GATA6 and LOXL2 were associated with poor prognosis in patients with CCA $(38,39)$. In the present study, the coexpression of GATA6 and LOXL2 in CCA was analyzed using TMAs. The 2-year survival rate of GATA6/LOXL2-positive patients was significantly lower than that of GATA6/LOXL2-negative patients (16 vs. 39\%; $\mathrm{P}=0.03$; Table I). According to the results of the Kaplan-Meier analysis, patients with CCA with GATA6/LOXL2-positive staining exhibited worse overall survival $(\mathrm{P}=0.01$; Fig. $1 \mathrm{C})$ and shorter disease-free survival $(\mathrm{P}=0.02$; Fig. 1D) than patients with $\mathrm{CCA}$ with GATA6/LOXL2-negative staining. Using Cox regression analysis to assess hazard ratios (HRs) for age, sex, tumor location, TNM stage and GATA6/LOXL2 expression, GATA6/LOXL2 expression was an independent predictor of poor overall survival and poor disease-free survival $(\mathrm{HR}=1.871,95 \% \mathrm{CI}=1.070-3.271$, $\mathrm{P}=0.028$, and $\mathrm{HR}=1.781,95 \% \mathrm{CI}=1.013-3.129, \mathrm{P}=0.045$, respectively; Table II). Additionally, advanced TNM stage(III-IV) was another independent predictor of overall survival and disease-free survival $(\mathrm{HR}=2.333,95 \% \mathrm{CI}=1.311-4.150$, $\mathrm{P}=0.004$, and $\mathrm{HR}=1.861,95 \% \mathrm{CI}=1.053-3.291, \mathrm{P}=0.033$, respectively; Table II). Collectively, these findings indicated that GATA6/LOXL2 expression was a risk factor for poor prognosis in patients with CCA.

Coexpression of GATA6 and LOXL2 associates with VEGFA expression and MVD in CCA samples. Anti-VEGFA and anti-CD34 antibodies were used to examine the associations between GATA6/LOXL2 and VEGFA expression, and between GATA6/LOXL2 expression and the MVD in CCA TMAs. VEGFA staining was observed in the cytoplasm (Fig. 1A). The weak and strong positive VEGFA classifications were defined as VEGFA-positive. CD34 was expressed in vascular endothelial cells and was used to determine the MVD (Fig. 1E). The mean value of MVD, defined as the cut-off value, was $23.69 / \mathrm{mm}^{2}$ in
Table I. Clinical characteristics of GATA6/LOXL2 expression in 66 patients with CCA.

\begin{tabular}{cc} 
GATA6/LOXL2 expression \\
\hline GATA6/ & GATA6/ \\
LOXL2- & LOXL2-
\end{tabular}

Characteristics positive (38) negative (28) P-value

\begin{tabular}{|c|c|c|c|}
\hline \multicolumn{4}{|l|}{ Age } \\
\hline$<60$ years & 22 & 16 & \multirow[t]{2}{*}{0.95} \\
\hline$\geq 60$ years & 16 & 12 & \\
\hline \multicolumn{4}{|l|}{ Sex } \\
\hline Male & 22 & 13 & \multirow[t]{2}{*}{0.36} \\
\hline Female & 16 & 15 & \\
\hline \multicolumn{4}{|c|}{ Location of tumor } \\
\hline Intrahepatic & 5 & 8 & \multirow[t]{2}{*}{0.12} \\
\hline Extrahepatic & 33 & 20 & \\
\hline \multicolumn{4}{|c|}{ Histological grade } \\
\hline G1 & 6 & 7 & \multirow[t]{3}{*}{0.46} \\
\hline G2 & 26 & 15 & \\
\hline G3 & 6 & 6 & \\
\hline \multicolumn{4}{|c|}{$\mathrm{T}_{\text {classification }}{ }^{\mathrm{a}}$} \\
\hline $\mathrm{T} 1$ or $\mathrm{T} 2$ & 25 & 21 & \multirow[t]{2}{*}{0.42} \\
\hline $\mathrm{T} 3$ or $\mathrm{T} 4$ & 13 & 7 & \\
\hline \multicolumn{4}{|c|}{ Lymph node metastasis } \\
\hline Negative & 18 & 21 & \multirow[t]{2}{*}{$0.02^{\mathrm{b}}$} \\
\hline Positive & 20 & 7 & \\
\hline \multicolumn{4}{|c|}{ TNM stage (UICC $\left.{ }^{a}\right)$} \\
\hline I or II & 13 & 17 & \multirow[t]{2}{*}{$0.03^{\mathrm{b}}$} \\
\hline III or IV & 25 & 11 & \\
\hline \multicolumn{4}{|l|}{ Survival } \\
\hline$\geq 2$ years & $6(16 \%)$ & $11(39 \%)$ & \multirow[t]{2}{*}{$0.03^{\mathrm{b}}$} \\
\hline$<2$ years & $32(84 \%)$ & $17(61 \%)$ & \\
\hline
\end{tabular}

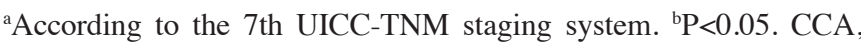
cholangiocarcinoma; GATA6, GATA-binding protein 6; LOXL2, lysyl oxidase-like 2; UICC, Union for International Cancer Control.

38 GATA6/LOXL2-positive and 28 GATA6/LOXL2-negative samples. Samples above the mean value were defined as exhibiting high MVD (40/66), and those below than the mean value as exhibiting low MVD (26/66; Fig. 1E). In the same TMA (Fig. 2A and B), 38 GATA6/LOXL2-positive tissues, $25(65.8 \%)$ VEGFA-positive tissues, and 27 (71.1\%) tissues with a high MVD were observed. Of note, GATA6/LOXL2 expression positively associated with VEGFA expression $(\mathrm{P}=0.02$; Table III) and MVD $(\mathrm{P}=0.04$; Table IV). Based on these findings, the coexpression of GATA6 and LOXL2 was significantly associated with VEGFA expression and MVD in human CCA samples.

GATA6 and LOXL2 influence VEGFA expression. Using the clinical data of patients, an association between GATA6/LOXL2 and VEGFA expression was identified in patients with CCA. GATA6 and LOXL2 protein levels were evaluated in two CCA 
A

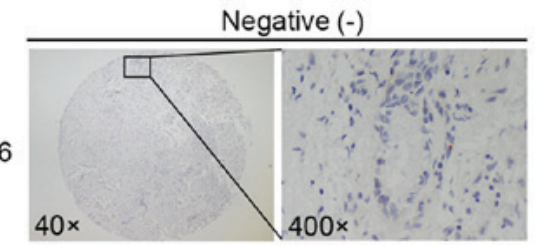

LOXL2

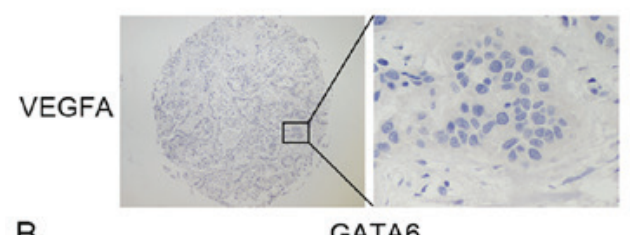

B

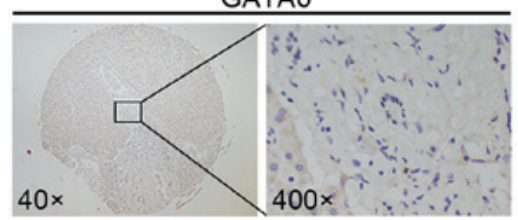

Weak positive (+)
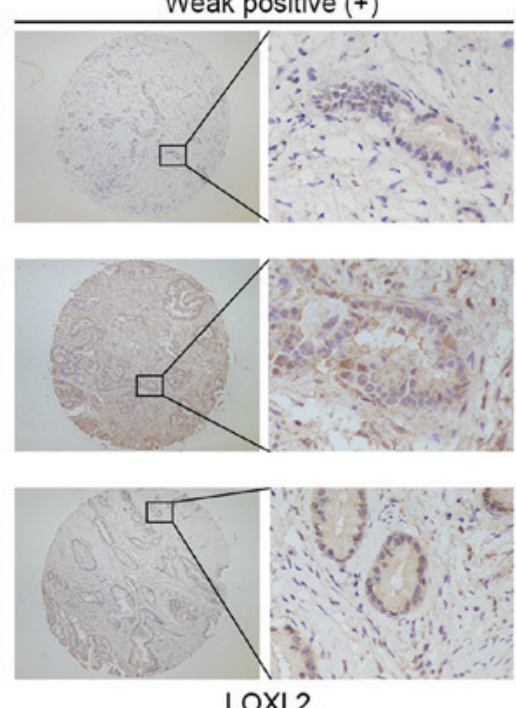

LOXL2

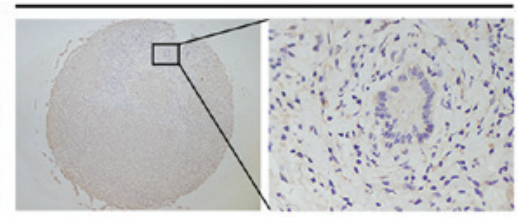

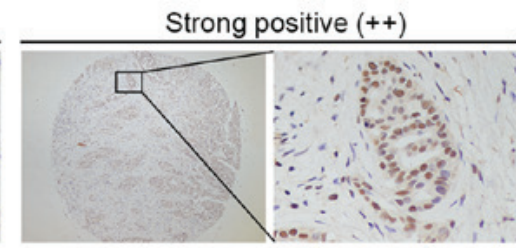
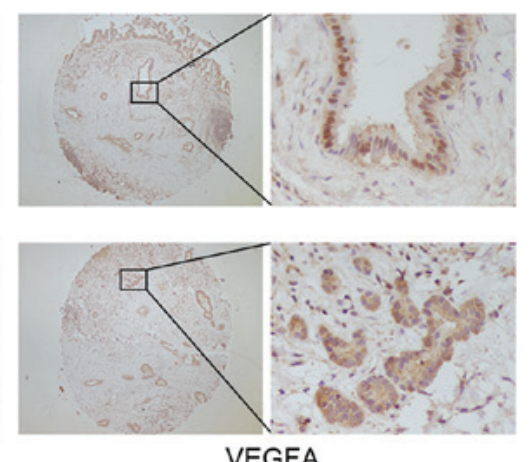

VEGFA

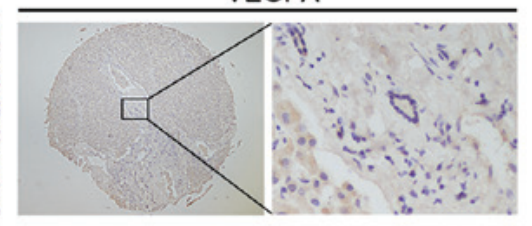

C

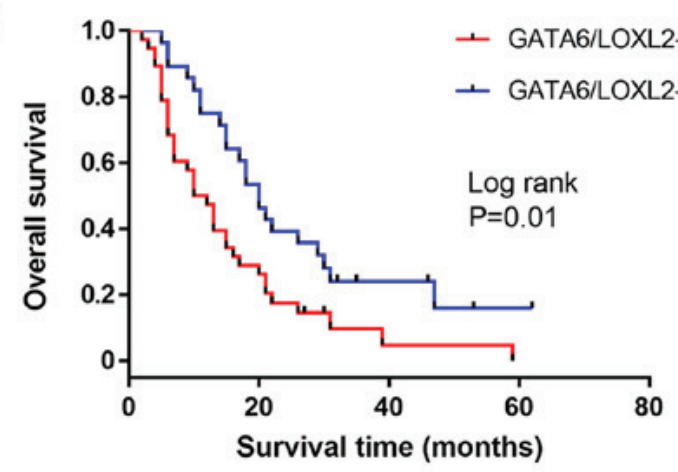

E
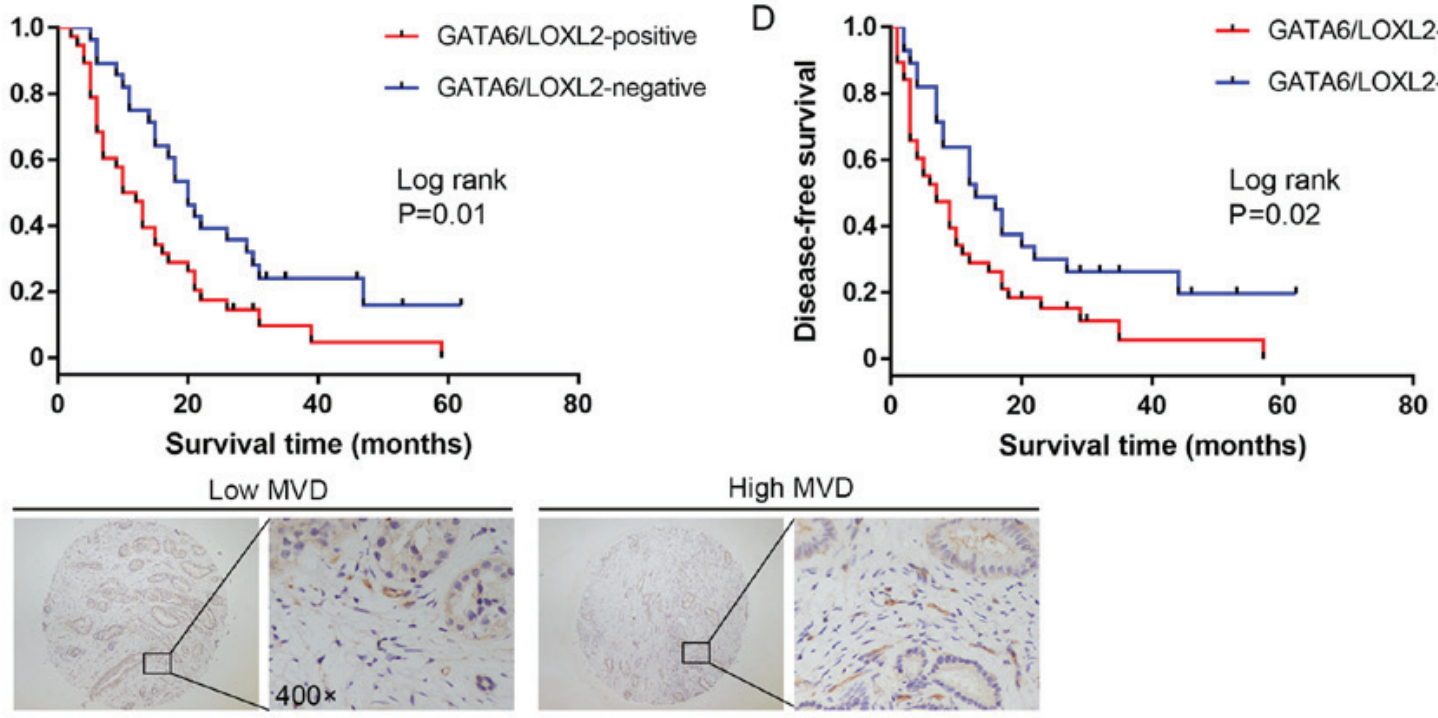

Figure 1. GATA6, LOXL2, and VEGFA expression and the MVD in TMAs from patients with CCA. TMAs were analyzed using immunohistochemistry. (A) Negative (-), weak positive (+) and strong positive (++) staining for GATA6, LOXL2, and VEGFA in CCA samples (magnifications, $x 40$ and $x 400$ ). (B) GATA6, LOXL2 and VEGFA expression in the bile duct epithelium of paracancerous tissue. Kaplan-Meier curves for (C) overall survival and (D) disease-free survival of CCA patients with GATA6/LOXL2-positive $(n=38)$ and GATA6/LOXL2-negative $(n=28)$ expression. (E) CD34 staining to determine MVD in CCA TMAs (magnifications, x40 and x400). CCA, cholangiocarcinoma; GATA6, GATA-binding protein 6; LOXL2, lysyl oxidase-like 2; MVD, microvessel density; TMA, tissue microarray; VEGFA, vascular endothelial growth factor A.

cell lines, QBC939 and RBE cells, to investigate this association in vitro. Increased levels of GATA6 and LOXL2 were observed in QBC939 cells compared with in RBE cells (Fig. S1A and B). These results were consistent with findings from our previous studies $(38,39)$. Therefore, GATA6 and LOXL2 expression was knocked down in QBC939 cells by transfecting lentiviruses carrying GATA6-shRNA or LOXL2-shRNA, and GATA6 and LOXL2 were overexpressed in RBE cells transfected with GATA6 and LOXL2-encoding lentiviruses. The effects of GATA6 and LOXL2 on VEGFA expression were then assessed. VEGFA protein levels were significantly increased in
RBE cells overexpressing GATA6 and LOXL2 (Fig. 3B and D) but were reduced in QBC939 cells with GATA6 and LOXL2 knockdown (Fig. 3C and E). Similar changes in mRNA expression were observed in CCA cells (Fig. 3B-E); however, no regulatory association between GATA6 and LOXL2 was detected (Fig. S2A and B). Thus, GATA6 and LOXL2 regulate VEGFA expression in human CCA cells.

LOXL2 physically interacts with GATA6 in CCA cell lines. The localization of the two proteins was determined via confocal laser scanning microscopy to confirm that GATA6 interacted 
Table II. Cox regression analysis for overall survival and disease-free survival of CCA following surgical resection.

\begin{tabular}{lcccc}
\hline & \multicolumn{2}{c}{ Overall survival } & & Disease-free survival \\
\cline { 2 - 3 } Factors & HR $(95 \% \mathrm{CI})$ & P-value & HR (95\% CI) & P-value \\
\hline GATA6/LOXL2 expression (positive/negative) & $1.871(1.070-3.271)$ & $0.028^{\mathrm{b}}$ & $1.781(1.013-3.129)$ & $0.045^{\mathrm{b}}$ \\
TNM stage (III-IV or I-II) & $2.333(1.311-4.150)$ & $0.004^{\mathrm{b}}$ & $1.861(1.053-3.291)$ & $0.033^{\mathrm{b}}$ \\
Sex (male or female) & $0.787(0.456-1.359)$ & 0.390 & $0.738(0.425-1.285)$ & 0.283 \\
Age ( $\geq 60$ years or <60 years) & $0.593(0.327-1.073)$ & 0.084 & $0.597(0.329-1.086)$ & 0.091 \\
Location (intrahepatic or extrahepatic) & $0.730(0.358-1.488)$ & 0.386 & $0.745(0.369-1.505)$ & 0.412 \\
\hline
\end{tabular}

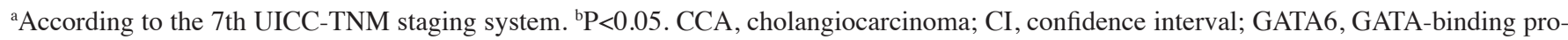
tein 6; HR, hazard ratio; LOXL2, lysyl oxidase-like 2; UICC, Union for International Cancer Control.

A

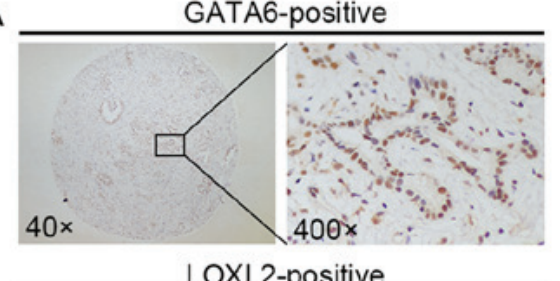

LOXL2-positive

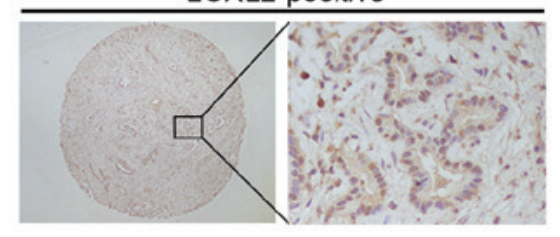

B

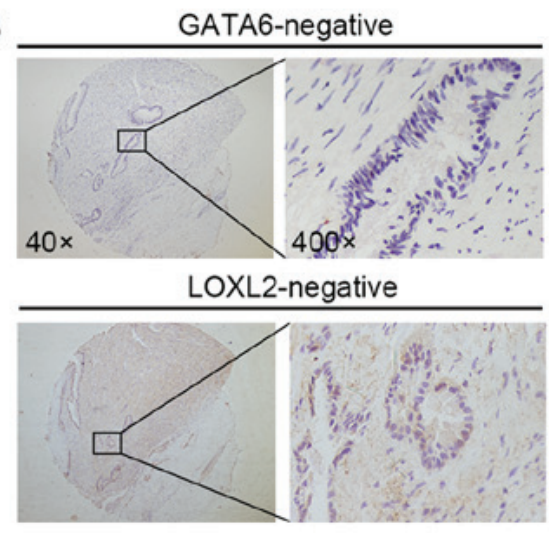

VEGFA-positive

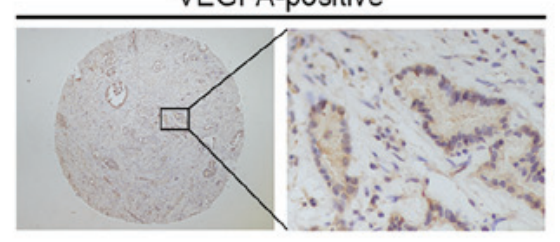

VEGFA-negative

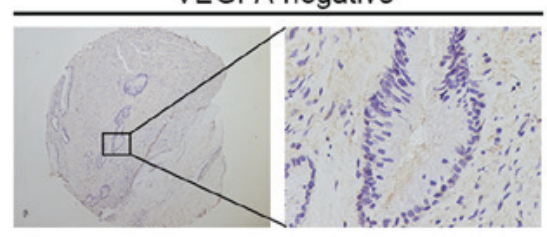

High MVD

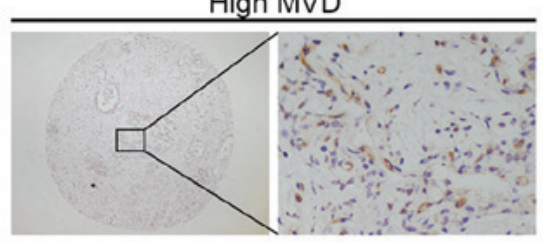

Low MVD

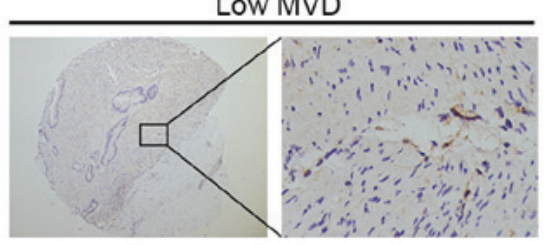

Figure 2. Expression of GATA6/LOXL2 in CCA samples, and associations with VEGFA expression and the MVD. (A) GATA6/LOXL2-positive expression, VEGFA-positive expression, and a high MVD in the same CCA samples. (B) GATA6/LOXL2-negative expression, VEGFA-negative expression, and a low MVD in the same CCA samples. CCA, cholangiocarcinoma; GATA6, GATA-binding protein 6; LOXL2, lysyl oxidase-like 2; MVD, microvessel density; VEGFA, vascular endothelial growth factor A.

with LOXL2. In CCA cells, GATA6 was located in the nucleus, and LOXL2 was located in the nucleus and cytoplasm. These results are consistent with the IHC staining of CCA tissues (Fig. 3A). A co-IP experiment was then performed using protein extracts from QBC939 and RBE cells. IP with an anti-GATA6 antibody resulted in the successful co-IP of LOXL2 in both cell lines (Fig. 4A and C). Similarly, an anti-LOXL2 antibody also successfully immunoprecipitated GATA6 in both cell lines (Fig. 4B and D). Interactions between GATA6 and LOXL2 in QBC939 and RBE cells were observed in co-IP experiments, revealing that GATA6 and LOXL2 physically interact in CCA cell lines.
GATA6/LOXL2 induce VEGFA transcription and bind to the VEGFA promoter. A plasmid in which the VEGFA promoter was inserted upstream of the luciferase gene was generated, and dual-luciferase reporter assays were performed to examine the regulatory activities of GATA6 and LOXL2 at the VEGFA promoter, and to investigate the underlying mechanisms via which these protein regulate VEGFA expression at the transcriptional level. Knockdown of GATA6 or LOXL2 significantly decreased VEGFA promoter activity compared with the control $(\mathrm{P}<0.05$ and $\mathrm{P}<0.05$, respectively), and knockdown of both GATA6 and LOXL2 further significantly decreased promoter activity compared with GATA6, 

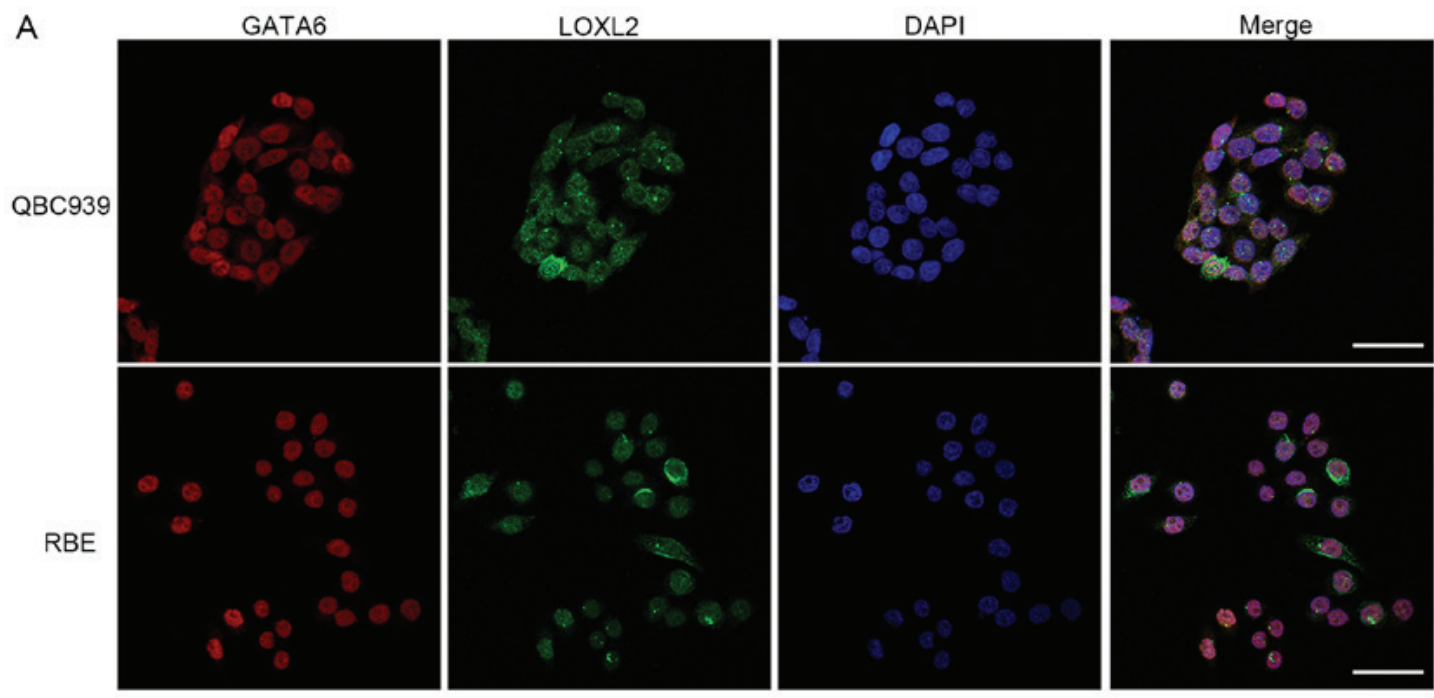

B
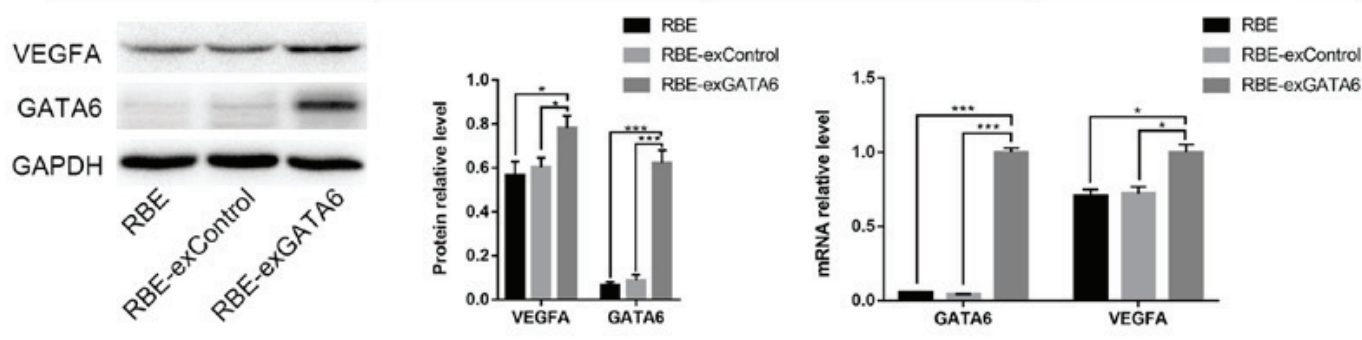

C
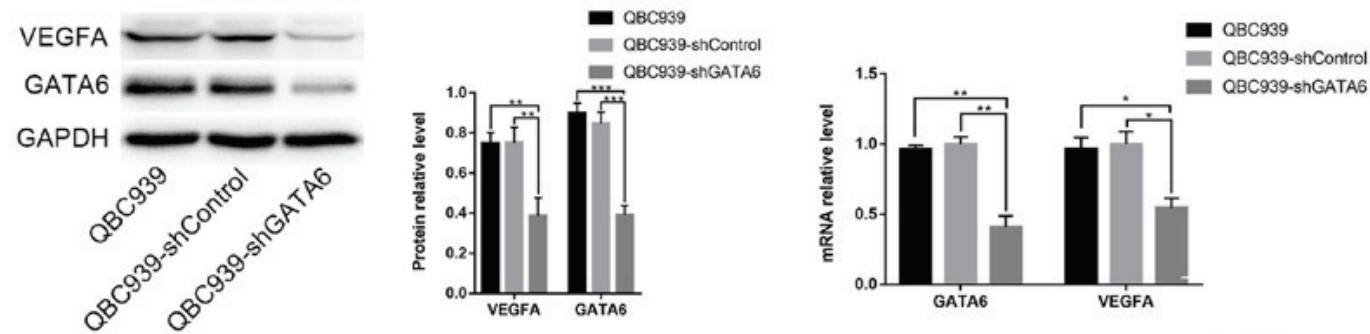

D
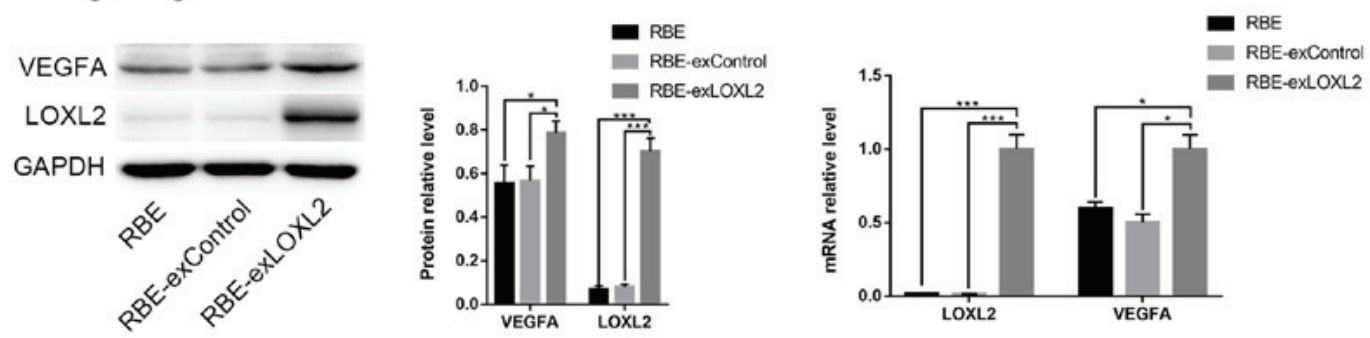

E
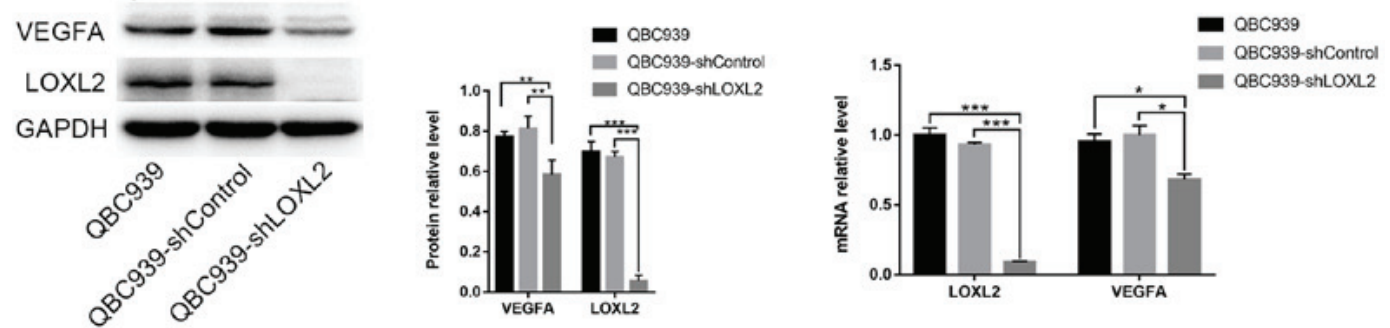

Figure 3. GATA6 and LOXL2 localization in human CCA cell lines, and regulation of VEGFA expression. (A) Confocal laser scanning microscopy was used to determine the localization of GATA6 (red) and LOXL2 (green) in QBC939 cells (upper panels) and RBE cells (lower panels). Scale bar, $50 \mu \mathrm{m}$. (B and C) Effects of altered GATA6 expression on VEGFA protein and mRNA levels in CCA cells, as determined via western blot and RT-qPCR analyses. (D and E) Effects of altered LOXL2 expression on VEGFA protein and mRNA levels in CCA cells, as determined via western blot and RT-qPCR analyses. GAPDH served as an internal control. All assays were performed in three independent experiments. Data are presented as the mean $\pm \mathrm{SEM}$. ${ }^{*} \mathrm{P}<0.05$, ${ }^{* *} \mathrm{P}<0.01$, ${ }^{* * *} \mathrm{P}<0.001$. CCA, cholangiocarcinoma; ex, overexpression vector; exControl, empty vector; GATA6, GATA-binding protein 6; LOXL2, lysyl oxidase-like 2; RT-qPCR, reverse transcription-quantitative PCR; sh, short hairpin (RNA); VEGFA, vascular endothelial growth factor A.

LOXL2 or shControl alone $(\mathrm{P}<0.01, \mathrm{P}<0.01$ and $\mathrm{P}<0.001$, respectively; Fig. 4E). In addition, whether GATA6 and
LOXL2 activate the VEGFA promoter was evaluated. VEGFA promoter activity was increased in cells overexpressing 
A
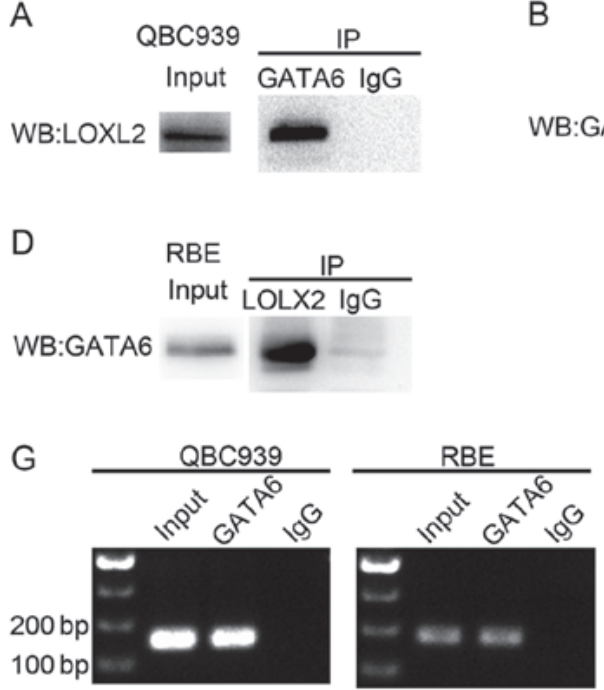

B
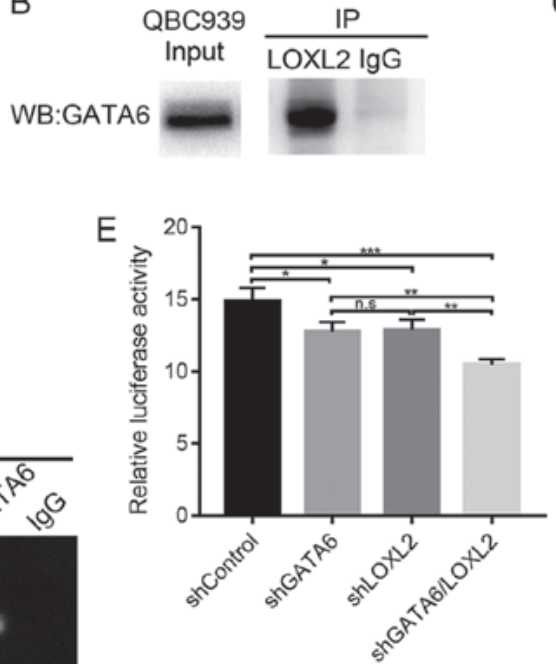

C

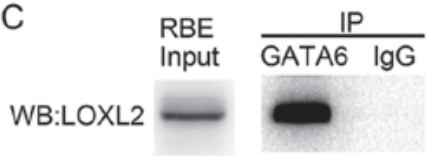

$\mathrm{F}$

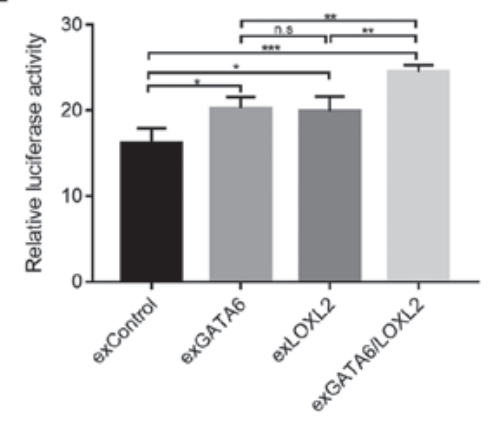

Figure 4. LOXL2 physically interacts with GATA6 and transcriptionally activates VEGFA expression in human CCA cell lines. Whole-cell lysates were extracted from CCA cells. Co-IP assays of (A and C) GATA6 and (B and D) LOXL2 were performed in (A and B) QBC939 and (C and D) RBE cells. IP with IgG antibodies served as a negative control. Western blotting was performed with anti-LOXL2 and anti-GATA6 antibodies. (E and F) Effects of altered GATA6/LOXL2 expression on luciferase activity driven by the VEGFA promoter, as analyzed using dual-luciferase reporter assays. (G) GATA6 binds to the VEGFA promoter, as determined using ChIP assays. All assays were performed in three independent experiments. Data are presented as the mean \pm SEM. ${ }^{*} \mathrm{P}<0.05,{ }^{* *} \mathrm{P}<0.01,{ }^{* * *} \mathrm{P}<0.001$; n.s., not significant. CCA, cholangiocarcinoma; (Ch/Co-)IP, (Chromatin/Co-)immunoprecipitation; ex, overexpression vector; exControl, empty vector; GATA6, GATA-binding protein 6; IgG, immunoglobulin G; LOXL2, lysyl oxidase-like 2; sh, short hairpin (RNA); VEGFA, vascular endothelial growth factor A; WB, western blot.

GATA6 or LOXL2 ( $\mathrm{P}<0.05$ and $\mathrm{P}<0.05$, respectively), and the simultaneous overexpression of GATA6 and LOXL2 significantly increased VEGFA promoter activity compared with the overexpression of GATA6 $(\mathrm{P}<0.01)$, LOXL2 $(\mathrm{P}<0.01)$, or exControl alone $(\mathrm{P}<0.001$; Fig. $4 \mathrm{~F})$.

GATA6 is a transcription factor, whereas LOXL2 is not. Thus, ChIP analysis was performed using the GATA6 antibody; it was observed that GATA6 bound to VEGFA promoter regions in QBC939 and RBE cells (Fig. 4G). Thus, GATA6 and LOXL2 may physically interact with each other and cooperatively target the VEGFA promoter in CCA cells.

LOXL2 interacts with GATA6 to promote VEGFA promoter activity in a manner dependent on the SRCR domain. The SRCR domain of LOXL2 interacts with other proteins (43). Two LOXL2 deletion mutants lacking or retaining the SRCR domain were constructed to further explore the interaction between LOXL2 and GATA6 (Fig. 5A). Based on the results from the co-IP experiment, GATA6 bound to the SRCR domain of LOXL2 independent of the catalytic domain in CCA cells (Fig. 5B and C). Additionally, Flag-LOXL2- $\Delta 1$ and Flag-LOXL2-full significantly increased VEGFA promoter activity compared with the control $(\mathrm{P}<0.05$ and $\mathrm{P}<0.05$, respectively); however, Flag-LOXL2- $\Delta 2$ did not increase VEGFA promoter activity (Fig. 5D). In addition, knockdown of GATA6 or LOXL2 in QBC939 cells decreased the interaction of LOXL2 with GATA6 (Fig. 5E and F). Based on the data, the SRCR domain of LOXL2 interacts with GATA6 to increase VEGFA promoter activity.

GATA6/LOXL2 promote VEGFA secretion from CCA cells and HUVEC capillary tube formation in vivo. VEGFA secreted by tumor cells promotes the proliferation and migration of vascular endothelial cells and tumor angiogenesis in the tumor microenvironment. CM was collected from QBC939 cells following transduction with shRNA lentivirus, and ELISAs were performed to evaluate the VEGFA concentration and determine whether GATA6/LOXL2 affected VEGFA secretion and angiogenesis. Significantly reduced levels of VEGFA were secreted from cells in the shGATA6/LOXL2 group compared with those in the shGATA6 $(\mathrm{P}<0.05)$, shLOXL2 $(\mathrm{P}<0.05)$ and shControl $(\mathrm{P}<0.001)$ groups (Fig. 6A).

Matrigel-based capillary tube formation assays were performed in HUVECs using CM from CCA cell lines to investigate whether GATA6/LOXL2 promoted angiogenesis in vitro. Different $\mathrm{CM}$ samples were added to Matrigel-coated wells, and HUVECs were added to the wells and allowed to form capillary tubes. Tube formation was significantly reduced in the shGATA6/LOXL2 group compared with in the shGATA6 $(\mathrm{P}<0.01)$, shLOXL2 $(\mathrm{P}<0.01)$ and shControl $(\mathrm{P}<0.001)$ groups (Fig. 6B).

GATA6 and LOXL2 promote angiogenesis and tumor growth in subcutaneous tumors in nude mice. Stable lentivirus-transduced CCA cell lines were established and subcutaneously injected into nude mice. After 4 weeks, the nude mice were sacrificed; the subcutaneous tumors were surgically removed, and measurements were obtained. The tumors were also sectioned and subjected to H\&E staining and IHC (Fig. 7A). IHC revealed GATA6 expression in the nucleus and LOXL2 expression in the nucleus and cytoplasm of tumor tissues (Fig. 7A), consistent with the IHC results for human CCA tissues and IF staining of human CCA cell lines. Knockdown of GATA6 or LOXL2 reduced VEGFA expression compared with the control, and knockdown of GATA6/LOXL2 markedly reduced VEGFA expression compared with the other groups (Fig. 7A); however, IHC did not reveal an association between GATA6 and LOXL2 expression (Fig. 7A). 

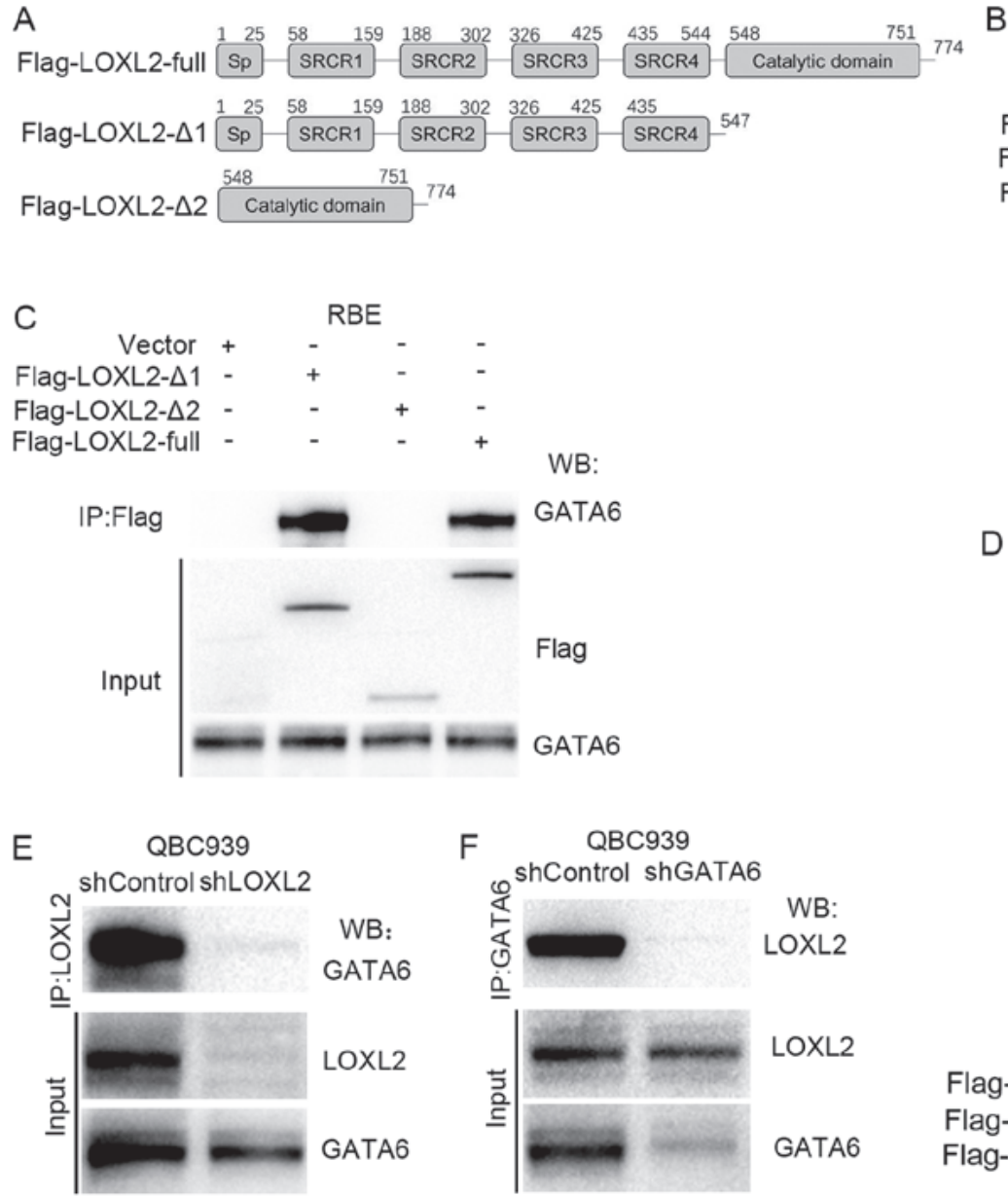

B

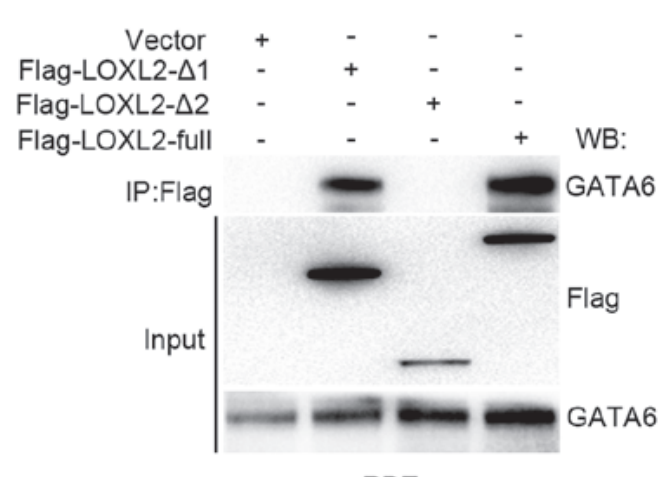

D

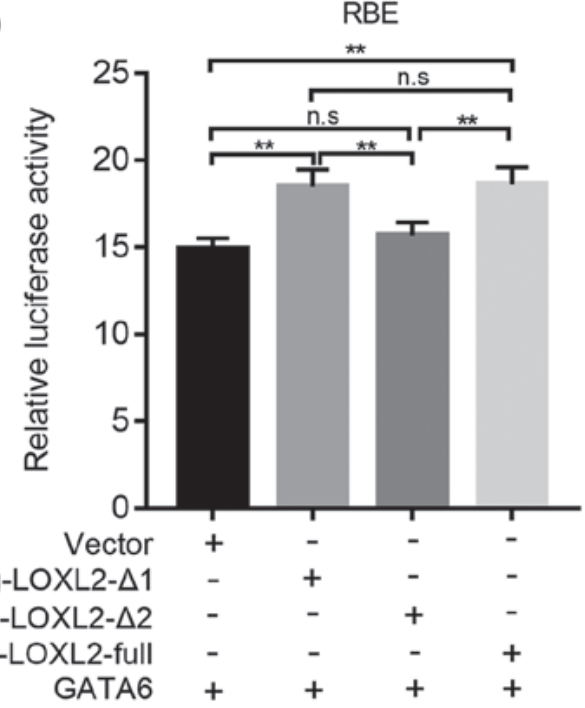

Figure 5. SRCR domain of LOXL2 interacts with GATA6 to increase VEGFA promoter activity. (A) Structural organization of different deletion mutant and full-length LOXL2 fusion proteins. (B) QBC939 and (C) RBE cells were transfected with the indicated plasmids, and cell lysates were immunoprecipitated with the Flag antibody, and then subjected to western blot analysis with an anti-GATA6 antibody. (D) Activity of the VEGFA promoter in RBE cells transfected with the indicated plasmids. QBC939 cells were transduced with the (E) shLOXL2 and (F) shGATA6 lentiviruses, and cell lysates were immunoprecipitated with the LOXL2 or GATA6 antibody and then subjected to WB analysis with anti-LOXL2 or anti-GATA6 antibodies. All assays were repeated three independent times. Data are presented as the mean \pm SEM. ${ }^{* *} \mathrm{P}<0.01$; n.s., not significant. GATA6, GATA-binding protein 6; IP, immunoprecipitation; LOXL2, lysyl oxidase-like 2; sh, short hairpin (RNA); Sp, signal peptide; SRCR, scavenger receptor cysteine-rich domain; VEGFA, vascular endothelial growth factor A; WB, western blot.

The MVD in the shGATA6/LOXL2 group was significantly reduced compared with that in the shGATA6 $(\mathrm{P}<0.01)$, shLOXL2 $(\mathrm{P}<0.01)$ and shControl $(\mathrm{P}<0.001)$ groups (Fig. 7B). Furthermore, the tumors in the shGATA6/LOXL2 group were significantly smaller than those in the shGATA6 $(\mathrm{P}<0.001)$, shLOXL2 $(\mathrm{P}<0.001)$ and shControl $(\mathrm{P}<0.001)$ groups (Fig. 7C). Thus, the findings indicated that GATA6/LOXL2 induced VEGFA expression, tumor growth and angiogenesis in subcutaneous tumors in nude mice.

\section{Discussion}

CCA is one of most highly aggressive malignant tumors, and only a minority of patients present with resectable disease. Furthermore, CCA relapse rates are high, and the 5-year survival rate is $5-15 \%(44,45)$. Antiangiogenic therapy has become a hot research topic. VEGFA is the central mediator of angiogenesis and is overexpressed in CCA $(46,47)$. Although antiangiogenesis therapy has achieved certain therapeutic benefits in patients with advanced CCA, high toxicity has been reported $(18,19)$. Therefore, the mechanisms underlying angiogenesis in CCA require further elucidation. In this study, the expression of both GATA6 with LOXL2 were analyzed to determine the clinical prognosis of patients with CCA; it was observed that this combination represented an independent prognostic indicator. In vitro, it was revealed that LOXL2 interacted with GATA6 to regulate VEGFA transcription and promote VEGFA secretion and angiogenesis. By analyzing subcutaneous tumors in nude mice, the associations between GATA6/LOXL2, and VEGFA and angiogenesis were further demonstrated.

GATA6 induced VEGFA mRNA expression and promoted angiogenesis in CCA. In previous studies, GATA6 was revealed to be important for the development of the cardiovascular system during the embryonic period (48), and the expression and secretion of VEGF were reduced in GATA6-null embryonic stem cells (49). GATA6 promotes angiogenesis in epithelial cells, at least in part by downregulating the transforming growth factor $\beta$ signaling pathway (29). According to the Gene Ontology database, GATA6 is a transcription factor that stimulates angiogenesis in late endothelial progenitor cells (31). Furthermore, GATA6 promotes the invasion and 
A

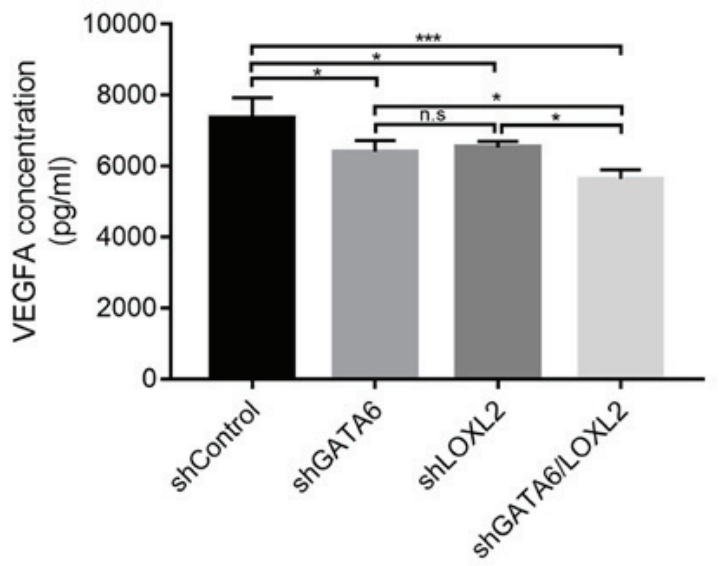

B
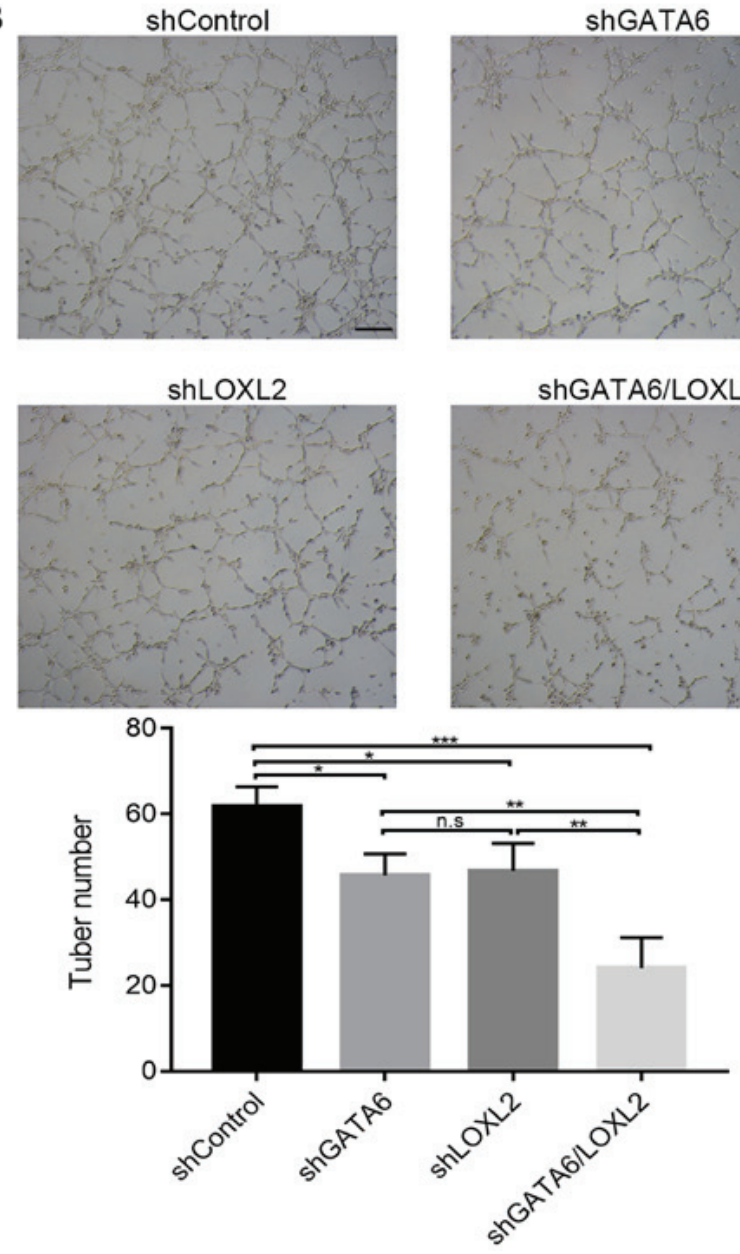

Figure 6. GATA6/LOXL2 promotes VEGFA secretion and angiogenesis (A) Concentrations of VEGFA protein secreted into the CM collected from QBC939 cells infected with shRNA lentivirus were detected by ELISA. (B) GATA6/LOXL2 knockdown suppressed tube formation by human umbilical vein endothelial cells cultured with CM. Representative photographs of tube-like structures were captured, and the mean numbers of tubes in the entire field were calculated. All assays were performed in three independent experiments. Scale bar, $200 \mu \mathrm{m}$. Data are presented as the mean $\pm \mathrm{SEM}$. ${ }^{*} \mathrm{P}<0.05,{ }^{* *} \mathrm{P}<0.01,{ }^{* * *} \mathrm{P}<0.001 ;$ n.s., not significant. CM, conditioned medium; GATA6, GATA-binding protein 6; LOXL2, lysyl oxidase-like 2; sh, short hairpin (RNA); VEGFA, vascular endothelial growth factorA.

metastasis of digestive cancer by regulating the transcription of target genes $(26,38,50)$. Chia et al (51) also reported that the interaction between GATA6 and GATA4 and Krueppel-like factor 5 promoted gastric cancer development; however, the
Table III. Association between GATA6/LOXL2 expression and VEGFA expression.

\begin{tabular}{lccc}
\hline & \multicolumn{2}{c}{$\begin{array}{c}\text { Expression of } \\
\text { GATA6/LOXL2 }\end{array}$} & \\
\cline { 2 - 3 } Factor & Positive & Negative & P-value \\
\hline $\begin{array}{l}\text { VEFGA expression } \\
\text { Positive }\end{array}$ & & & $0.02^{\mathrm{a}}$ \\
Negative & $25(65.8 \%)$ & $10(35.7 \%)$ & \\
\hline
\end{tabular}

${ }^{a} \mathrm{P}<0.05$. GATA6, GATA-binding protein 6; LOXL2, lysyl oxidaselike 2; VEGFA, vascular endothelial growth factor A.

Table IV. Associations between GATA6/LOXL2 expression and the MVD.

\begin{tabular}{cccc}
\hline & \multicolumn{2}{l}{ Expression of GATA6/LOXL2 } & \\
\cline { 2 - 3 } Factor & Positive & Negative & P-value \\
\hline MVD & & $0.04^{\mathrm{a}}$ \\
High & $27(71.1 \%)$ & $13(46.4 \%)$ & \\
Low & $11(28.9 \%)$ & $15(53.6 \%)$ & \\
\hline
\end{tabular}

${ }^{a} \mathrm{P}<0.05$. GATA6, GATA-binding protein 6; LOXL2, lysyl oxidaselike 2; MVD, microvessel density.

mechanisms via which GATA6 regulates VEGFA transcription are yet to be reported. In the present study, it was revealed that GATA6 bound to the VEGFA promoter, and that LOXL2 physically interacted with GATA6.

Additionally, the GATA6/LOXL2 complex induced the expression and secretion of VEGFA, angiogenesis and tumor growth. LOXL2 was initially isolated from senescent human fibroblasts and revealed to be involved in extracellular matrix crosslinking and cellular adhesion (52). Increased LOXL2 expression is associated with poor prognosis in patients with breast cancer (53), lung squamous cell carcinoma (54) and cholangiocarcinoma (39). LOXL2 promotes tumor invasion and metastasis via extracellular and intracellular mechanisms. Secreted LOXL2 enhanced tumor invasion and angiogenesis in the tumor microenvironment by activating the Src/focal adhesion kinase pathway (55) and collagen IV scaffolding (56). Intracellular LOXL2 repressed E-cadherin expression by stabilizing the transcription factor Snail, subsequently inducing EMT (34). In addition, the LOXL2 inhibitor AB0023, a LOXL2-specific monoclonal antibody, inhibited tumor growth and angiogenesis in mice (37). The present study is the first to report cellular LOXL2 as a novel partner of GATA6, and the involvement of the complex in the mechanism regulating VEGFA expression and angiogenesis.

It was determined that LOXL2 interacted with GATA6 and bound to the VEGFA promoter, and that the SRCR domain of LOXL2 interacted with GATA6 independently of the catalytic domain. Further studies are required to determine which SRCR domain interacts with GATA6. The interaction of 

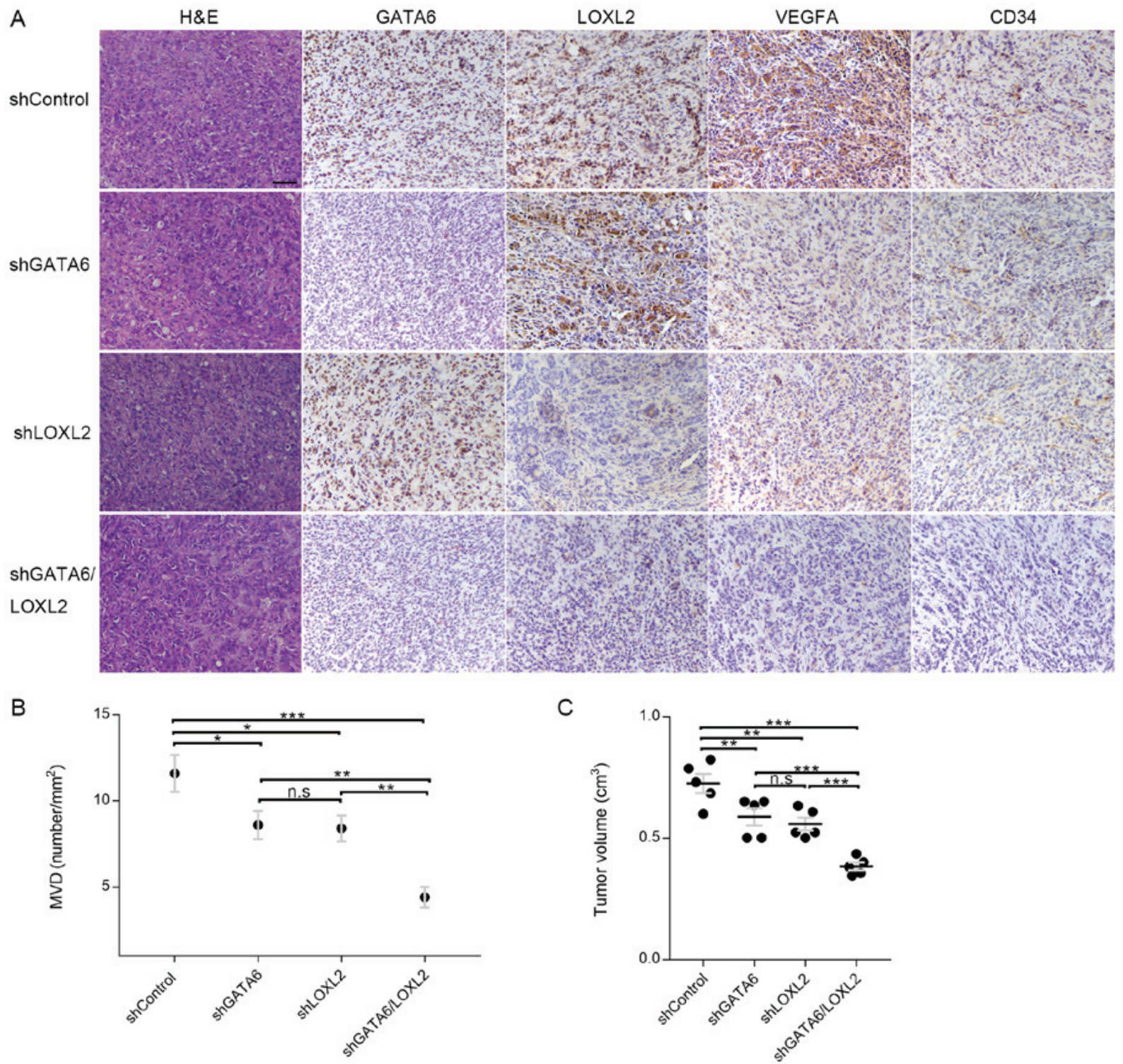

Figure 7. GATA6/LOXL2 complex promotes VEGFA expression, tumor growth and angiogenesis in CCA subcutaneous tumors in nude mice. (A) CCA subcutaneous tumors were confirmed by H\&E staining. Representative images of IHC staining for GATA6, LOXL2, VEGFA, and CD34 in subcutaneous tumors from different groups of nude mice. Scale bar, $50 \mu \mathrm{m}$. (B) GATA6/LOXL2 knockdown decreases the MVD. (C) GATA6/LOXL2 knockdown reduces tumor growth. Data are presented as the mean $\pm \mathrm{SEM} .{ }^{*} \mathrm{P}<0.05,{ }^{* *} \mathrm{P}<0.01,{ }^{* * * *} \mathrm{P}<0.001$; n.s., not significant. CCA, cholangiocarcinoma; GATA6, GATA-binding protein 6; $\mathrm{H} \& \mathrm{E}$, hematoxylin and eosin; LOXL2, lysyl oxidase-like 2; MVD, microvessel density; sh, short hairpin (RNA); VEGFA, vascular endothelial growth factor A

LOXL2 with GATA6 in the nucleus served a role in regulating transcription; however, based on the IHC analysis of human CCA tissues and IF analysis of CCA cell lines, LOXL2 is also located in the cytoplasm. Thus, further investigations are required to determine whether cytoplasmic LOXL2 regulates VEGFA expression in CCA via specific signaling pathways. Additionally, other LOXL2-interacting partners in the nucleus also require identification.

In summary, the present study identified a novel molecular mechanism for increased angiogenesis resulting from the interaction between LOXL2 and GATA6 that enhances VEGFA expression, and promotes angiogenesis and tumor growth. The development of novel candidate prognostic markers for the stratification of patients with CCA and of small-molecule, cell-permeable inhibitors that target both intracellular and extracellular LOXL2 are likely to have great therapeutic value.

\section{Acknowledgements}

We thank Professor Wanchun Luo (Statistics Department, Military Preventive Medicine, Army Medical University), for their assistance with statistical analyses.

\section{Funding}

This study was supported by grants from the National Natural Science Foundation of China (grant no. 81572456) and the Natural Science Foundation of Southwest Hospital (grant no. Swh2016yscxzd-02).

\section{Availability of data and materials}

The datasets used and analyzed in the current study are available from the corresponding author upon reasonable request. 


\section{Authors' contributions}

TP performed and analyzed the experiments, and drafted the manuscript. XD, ZL, FT, PJ, XZ and YC were involved in performing the experiments. GC and PZ prepared the materials and contributed to data acquisition. ZL, XD and FT assisted in correcting the manuscript. SW and DL designed and supervised the study. All authors have read and approved the final manuscript.

\section{Ethics approval and consent to participate}

This study was approved by the Ethics Committee of Southwest Hospital at Army Medical University. All participants signed informed consent forms.

\section{Patient consent for publication}

Not applicable.

\section{Competing interests}

The authors declare that they have no competing interests.

\section{References}

1. Welzel TM, McGlynn KA, Hsing AW, O'Brien TR and Pfeiffer RM: Impact of classification of hilar cholangiocarcinomas (Klatskin tumors) on the incidence of intra- and extrahepatic cholangiocarcinoma in the United States. J Natl Cancer Inst 98 : 873-875, 2006

2. Rizvi S and Gores GJ: Pathogenesis, diagnosis, and management of cholangiocarcinoma. Gastroenterology 145: 1215-1229, 2013.

3. Khan SA, Taylor-Robinson SD, Toledano MB, Beck A, Elliott P and Thomas HC: Changing international trends in mortality rates for liver, biliary and pancreatic tumours. J Hepatol 37: 806-813, 2002.

4. Jarnagin WR, Fong Y, DeMatteo RP, Gonen M, Burke EC, Bodniewicz BS J, Youssef BA M, Klimstra D and Blumgart LH Staging, resectability, and outcome in 225 patients with hilar cholangiocarcinoma. Ann Surg 234: 507-519, 2001.

5. Valle J, Wasan H, Palmer DH, Cunningham D, Anthoney A, Maraveyas A, Madhusudan S, Iveson T, Hughes S, Pereira SP, et al; ABC-02 Trial Investigators: Cisplatin plus gemcitabine versus gemcitabine for biliary tract cancer. N Engl J Med 362: 1273-1281, 2010.

6. Jayson GC, Kerbel R, Ellis LM and Harris AL: Antiangiogenic therapy in oncology: Current status and future directions. Lancet 388: 518-529, 2016.

7. Hanahan D and Weinberg RA: Hallmarks of cancer: The next generation. Cell 144: 646-674, 2011

8. Butler JM, Kobayashi H and Rafii S: Instructive role of the vascular niche in promoting tumour growth and tissue repair by angiocrine factors. Nat Rev Cancer 10: 138-146, 2010.

9. Kim KJ, Li B, Winer J, Armanini M, Gillett N, Phillips HS and Ferrara N: Inhibition of vascular endothelial growth factor-induced angiogenesis suppresses tumour growth in vivo. Nature 362: 841-844, 1993.

10. Takahashi Y, Kitadai Y, Bucana CD, Cleary KR and Ellis LM: Expression of vascular endothelial growth factor and its receptor, KDR, correlates with vascularity, metastasis, and proliferation of human colon cancer. Cancer Res 55: 3964-3968, 1995.

11. Koh YW, Han JH, Yoon DH, Suh C and Huh J: PD-L1 expression correlates with VEGF and microvessel density in patients with uniformly treated classical Hodgkin lymphoma. Ann Hematol 96: 1883-1890, 2017.

12. Benckert C, Thelen A, Cramer T, Weichert W, Gaebelein G, Gessner R and Jonas S: Impact of microvessel density on lymph node metastasis and survival after curative resection of pancreatic cancer. Surg Today 42: 169-176, 2012.
13. Tynninen O, Sjöström J, von Boguslawski K, Bengtsson NO, Heikkilä R, Malmström P, Ostenstad B, Wist E, Valvere V, Saksela E, et al: Tumour microvessel density as predictor of chemotherapy response in breast cancer patients. Br J Cancer 86: 1905-1908, 2002.

14. Wang L,Zhou R, Zhao Y, Dong S,Zhang J,Luo Y,Huang N, Shi M, Bin J, Liao Y, et al: MACC-1 promotes endothelium-dependent angiogenesis in gastric cancer by activating TWIST1/VEGF-A signal pathway. PLoS One 11: e0157137, 2016.

15. Thelen A, Scholz A, Weichert W, Wiedenmann B, Neuhaus P, Gessner R, Benckert C and Jonas S: Tumor-associated angiogenesis and lymphangiogenesis correlate with progression of intrahepatic cholangiocarcinoma. Am J Gastroenterol 105: $1123-1132,2010$

16. Möbius C, Demuth C, Aigner T, Wiedmann M, Wittekind C, Mössner J, Hauss J and Witzigmann H: Evaluation of VEGF A expression and microvascular density as prognostic factors in extrahepatic cholangiocarcinoma. Eur J Surg Oncol 33: $1025-1029,2007$

17. Li Y, Gao ZH and Qu XJ: The adverse effects of sorafenib in patients with advanced cancers. Basic Clin Pharmacol Toxicol 116: 216-221, 2015.

18. El-Khoueiry AB, Rankin CJ, Ben-Josef E, Lenz HJ, Gold PJ, Hamilton RD, Govindarajan R, Eng $\mathrm{C}$ and Blanke CD SWOG 0514: A phase II study of sorafenib in patients with unresectable or metastatic gallbladder carcinoma and cholangiocarcinoma. Invest New Drugs 30: 1646-1651, 2012.

19. Pan TT, Wang W, Jia WD and Xu GL: A single-center experience of sorafenib monotherapy in patients with advanced intrahepatic cholangiocarcinoma. Oncol Lett 13: 2957-2964, 2017.

20. Li Y, Li S, Zhu Y, Liang X, Meng H, Chen J, Zhang D, Guo H and Shi B: Incidence and risk of sorafenib-induced hypertension: A systematic review and meta-analysis. J Clin Hypertens (Greenwich) 16: 177-185, 2014.

21. Abdel-Rahman $\mathrm{O}$ and ElHalawani H: Risk of cardiovascular adverse events in patients with solid tumors treated with ramucirumab: A meta analysis and summary of other VEGF targeted agents. Crit Rev Oncol Hematol 102: 89-100, 2016.

22. Alexandrovich A, Qureishi A, Coudert AE, Zhang L, Grigoriadis AE, Shah AM, Brewer AC and Pizzey JA: A role for GATA-6 in vertebrate chondrogenesis. Dev Biol 314: 457-470, 2008.

23. Molkentin JD: The zinc finger-containing transcription factors GATA-4, -5 , and -6 . Ubiquitously expressed regulators of tissue-specific gene expression. J Biol Chem 275: 38949-38952, 2000.

24. Pierce GB: The cancer cell and its control by the embryo. Rous-Whipple Award lecture. Am J Pathol 113: 117-124, 1983.

25. Sulahian R, Casey F, Shen J, Qian ZR, Shin H, Ogino S, Weir BA, Vazquez F, Liu XS, Hahn WC, et al: An integrative analysis reveals functional targets of GATA6 transcriptional regulation in gastric cancer. Oncogene 33: 5637-5648, 2014.

26. Tsuji S, Kawasaki Y, Furukawa S, Taniue K, Hayashi T, Okuno M, Hiyoshi M,Kitayama J and Akiyama T: The miR-363-GATA6-Lgr5 pathway is critical for colorectal tumourigenesis. Nat Commun 5: 3150, 2014.

27. Chen WB, Huang FT, Zhuang YY, Tang J, Zhuang XH, Cheng WJ, Gu ZQ and Zhang SN: Silencing of GATA6 suppresses SW1990 pancreatic cancer cell growth in vitro and up-regulates reactive oxygen species. Dig Dis Sci 58: 2518-2527, 2013.

28. Song Y, Tian T, Fu X, Wang W, Li S, Shi T, Suo A, Ruan Z, Guo H and Yao Y: GATA6 is overexpressed in breast cancer and promotes breast cancer cell epithelial-mesenchymal transition by upregulating slug expression. Exp Mol Pathol 99: 617-627, 2015.

29. Froese N, Kattih B, Breitbart A, Grund A, Geffers R, Molkentin JD, Kispert A, Wollert KC, Drexler H and Heineke J: GATA6 promotes angiogenic function and survival in endothelial cells by suppression of autocrine transforming growth factor beta/activin receptor-like kinase 5 signaling. J Biol Chem 286 5680-5690, 2011

30. Hou R, Yan H, Niu X, Chang W, An P, Wang C, Yang Y, Yan X, Li J, Liu R, et al: Gene expression profile of dermal mesenchymal stem cells from patients with psoriasis. J Eur Acad Dermatol Venereol 28: 1782-1791, 2014

31. Cheng CC, Chang SJ, Chueh YN, Huang TS, Huang PH, Cheng SM, Tsai TN, Chen JW and Wang HW: Distinct angiogenesis roles and surface markers of early and late endothelial progenitor cells revealed by functional group analyses. BMC Genomics 14: 182, 2013 
32. Kagan HM and Li W: Lysyl oxidase: Properties, specificity, and biological roles inside and outside of the cell. J Cell Biochem 88: 660-672, 2003.

33. Hohenester E, Sasaki T and Timpl R: Crystal structure of a scavenger receptor cysteine-rich domain sheds light on an ancient superfamily. Nat Struct Biol 6: 228-232, 1999.

34. Peinado H, Del Carmen Iglesias-de la Cruz M, Olmeda D, Csiszar K, Fong KS, Vega S, Nieto MA, Cano A and Portillo F: A molecular role for lysyl oxidase-like 2 enzyme in snail regulation and tumor progression. EMBO J 24: 3446-3458, 2005.

35. Canesin G, Cuevas EP, Santos V, López-Menéndez C, Moreno-Bueno G, Huang Y, Csiszar K, Portillo F, Peinado H, Lyden D, et al: Lysyl oxidase-like 2 (LOXL2) and E47 EMT factor: Novel partners in E-cadherin repression and early metastasis colonization. Oncogene 34: 951-964, 2015.

36. Van Bergen T, Spangler R, Marshall D, Hollanders K Van de Veire S, Vandewalle E, Moons L, Herman J, Smith V and Stalmans I: The role of LOX and LOXL2 in the pathogenesis of an experimental model of choroidal neovascularization. Invest Ophthalmol Vis Sci 56: 5280-5289, 2015.

37. Zaffryar-Eilot S, Marshall D, Voloshin T, Bar-Zion A, Spangler R, Kessler O, Ghermazien H, Brekhman V, Suss-Toby E, Adam D, et al: Lysyl oxidase-like-2 promotes tumour angiogenesis and is a potential therapeutic target in angiogenic tumours. Carcinogenesis 34: 2370-2379, 2013.

38. Tian F, Li D, Chen J, Liu W, Cai L, Li J, Jiang P, Liu Z, Zhao X, Guo F, et al: Aberrant expression of GATA binding protein 6 correlates with poor prognosis and promotes metastasis in cholangiocarcinoma. Eur J Cancer 49: 1771-1780, 2013.

39. Xu J, Li D, Li X, Liu Z, Li T, Jiang P, He Q, Tian F, Gao Y, Wang D, et al: 67 laminin receptor promotes the malignant potential of tumour cells up-regulating lysyl oxidase-like 2 expression in cholangiocarcinoma. Dig Liver Dis 46: 750-757, 2014.

40. Edge SBBD, Compton CC, Fritz AG, Greene FL and Trotti A AJCC Cancer Staging Manual. 7th edition. Springer, New York, NY, 2010.

41. Weidner N, Semple JP, Welch WR and Folkman J: Tumor angiogenesis and metastasis - correlation in invasive breast carcinoma. N Engl J Med 324: 1-8, 1991

42. Livak KJ and Schmittgen TD: Analysis of relative gene expression data using real-time quantitative PCR and the 2(-Delta Delta C(T)) method. Methods 25: 402-408, 2001.

43. Kim BR, Dong SM, Seo SH, Lee JH, Lee JM, Lee SH and Rho SB: Lysyl oxidase-like 2(LOXL2) controls tumor-associated cell proliferation through the interaction with MARCKSL1. Cell Signal 26: 1765-1773, 2014.

44. Anderson C and Kim R: Adjuvant therapy for resected extrahepatic cholangiocarcinoma: A review of the literature and future directions. Cancer Treat Rev 35: 322-327, 2009.

45. DeOliveira ML, Cunningham SC, Cameron JL, Kamangar F, Winter JM, Lillemoe KD, Choti MA, Yeo CJ and Schulick RD: Cholangiocarcinoma: Thirty-one-year experience with 564 patients at a single institution. Ann Surg 245: 755-762, 2007.
46. Yoshikawa D, Ojima H, Iwasaki M, Hiraoka N, Kosuge T, Kasai S, Hirohashi S and Shibata T: Clinicopathological and prognostic significance of EGFR, VEGF, and HER2 expression in cholangiocarcinoma. Br J Cancer 98: 418-425, 2008.

47. Glaser SS, Gaudio E and Alpini G: Vascular factors, angiogenesis and biliary tract disease. Curr Opin Gastroenterol 26: 246-250, 2010.

48. Xin M, Davis CA, Molkentin JD, Lien CL, Duncan SA, Richardson JA and Olson EN: A threshold of GATA4 and GATA6 expression is required for cardiovascular development. Proc Natl Acad Sci USA 103: 11189-11194, 2006.

49. Pierre M, Yoshimoto M, Huang L, Richardson M and Yoder MC: VEGF and IHH rescue definitive hematopoiesis in Gata-4 and Gata-6-deficient murine embryoid bodies. Exp Hematol 37: 1038-1053, 2009

50. Kawasaki Y, Matsumura K, Miyamoto M, Tsuji S, Okuno M, Suda S, Hiyoshi M, Kitayama J and Akiyama T: REG4 is a transcriptional target of GATA6 and is essential for colorectal tumorigenesis. Sci Rep 5: 14291, 2015.

51. Chia NY, Deng N, Das K, Huang D, Hu L, Zhu Y, Lim KH, Lee MH, Wu J, Sam XX, et al: Regulatory crosstalk between lineage-survival oncogenes KLF5, GATA4 and GATA6 cooperatively promotes gastric cancer development. Gut 64: 707-719, 2015.

52. Saito H, Papaconstantinou J, Sato H and Goldstein S: Regulation of a novel gene encoding a lysyl oxidase-related protein in cellular adhesion and senescence. J Biol Chem 272: 8157-8160, 1997.

53. Ahn SG, Dong SM, Oshima A, Kim WH, Lee HM, Lee SA, Kwon SH, Lee JH, Lee JM, Jeong J, et al: LOXL2 expression is associated with invasiveness and negatively influences survival in breast cancer patients. Breast Cancer Res Treat 141: 89-99, 2013.

54. Peinado H, Moreno-Bueno G, Hardisson D, Pérez-Gómez E, Santos V, Mendiola M, de Diego JI, Nistal M, Quintanilla M, Portillo F, et al: Lysyl oxidase-like 2 as a new poor prognosis marker of squamous cell carcinomas. Cancer Res 68: 4541-4550, 2008.

55. Peng L, Ran YL, Hu H, Yu L, Liu Q, Zhou Z, Sun YM, Sun LC, Pan J, Sun LX, et al: Secreted LOXL2 is a novel therapeutic target that promotes gastric cancer metastasis via the Src/FAK pathway. Carcinogenesis 30: 1660-1669, 2009.

56. Bignon M, Pichol-Thievend C, Hardouin J, Malbouyres M, Bréchot N, Nasciutti L, Barret A, Teillon J, Guillon E, Etienne E, et al: Lysyl oxidase-like protein-2 regulates sprouting angiogenesis and type IV collagen assembly in the endothelial basement membrane. Blood 118: 3979-3989, 2011.

This work is licensed under a Creative Commons Attribution-NonCommercial-NoDerivatives 4.0 International (CC BY-NC-ND 4.0) License. 